\title{
HOW TO FILL THE WORKING-AGE POPULATION GAP IN ASIA: A POPULATION ACCOUNTING APPROACH
}

Jong Woo Kang and Grendell Vie Magoncia

\section{NO. 499}

November 2016
ADB ECONOMICS WORKING PAPER SERIES 
ADB Economics Working Paper Series

\section{How to Fill the Working-Age Population Gap in Asia: A Population Accounting Approach}

Jong Woo Kang and Grendell Vie Magoncia

No. 499 | November 2016
Jong Woo Kang (jkang@adb.org) is principal economist at the Economic Research and Regional Cooperation Department (ERCD), Asian Development Bank. Grendell Vie Magoncia (gvmagoncia.consultant@adb.org) is a consultant at ERCD. 
(c) 2016 Asian Development Bank

6 ADB Avenue, Mandaluyong City, 1550 Metro Manila, Philippines

Tel +632632 4444; Fax +6326362444

www.adb.org

Some rights reserved. Published in 2016.

Printed in the Philippines.

ISSN 2313-6537 (Print), 2313-6545 (e-ISSN)

Publication Stock No. WPS168506-2

Cataloging-In-Publication Data

Asian Development Bank.

How to fill the working-age population gap in Asia: A population accounting approach.

Mandaluyong City, Philippines: Asian Development Bank, 2016.

1. Demographic shift. 2. Dependency ratio. 3. Fertility rate. 4. Migration. 5. Population accounting. I. Asian Development Bank.

The views expressed in this publication are those of the authors and do not necessarily reflect the views and policies of the Asian Development Bank (ADB) or its Board of Governors or the governments they represent.

$A D B$ does not guarantee the accuracy of the data included in this publication and accepts no responsibility for any consequence of their use. The mention of specific companies or products of manufacturers does not imply that they are endorsed or recommended by ADB in preference to others of a similar nature that are not mentioned.

By making any designation of or reference to a particular territory or geographic area, or by using the term "country" in this document, $A D B$ does not intend to make any judgments as to the legal or other status of any territory or area.

This work is available under the Creative Commons Attribution 3.0 IGO license (CC BY 3.0 IGO)

https://creativecommons.org/licenses/by/3.0/igo/. By using the content of this publication, you agree to be bound by the terms of this license.

This CC license does not apply to non-ADB copyright materials in this publication. If the material is attributed to another source, please contact the copyright owner or publisher of that source for permission to reproduce it. ADB cannot be held liable for any claims that arise as a result of your use of the material.

Attribution-You should always acknowledge ADB as the source using the following format:

[Author]. [Year of publication]. [Title of the work in italics]. [City of publication]: [Publisher]. ( ) ADB. [URL or DOI] [license].

Translations-Any translations you create should carry the following disclaimer:

Originally published by ADB in English under the title [title in italics]. (c) ADB. [URL or DOI] [license]. The quality of the translation and its coherence with the original text is the sole responsibility of the translator. The English original of this work is the only official version.

Adaptations-Any adaptations you create should carry the following disclaimer:

This is an adaptation of an original work titled [title in italics]. (c) ADB. [URL or DOI][license]. The views expressed here are those of the authors and do not necessarily reflect the views and policies of ADB or its Board of Governors or the governments they represent. ADB does not endorse this work or guarantee the accuracy of the data included in this publication and accepts no responsibility for any consequence of their use.

Please contact pubsmarketing@adb.org if you have questions or comments with respect to content, or if you wish to obtain copyright permission for your intended use that does not fall within these terms, or for permission to use the ADB logo.

Notes:

1. In this publication, "\$" refers to US dollars.

2. Corrigenda to ADB publications may be found at http://www.adb.org/publications/corrigenda 


\section{CONTENTS}

TABLES AND FIGURES iv

ABSTRACT $v$ V

$\begin{array}{ll}\text { I. INTRODUCTION } & 1\end{array}$

II. ASIA'S DEMOGRAPHIC CHANGE AND ECONOMIC IMPACT 2

A. $\quad$ Asia's Shifting Demographic Structure 2

B. Impact of Demographic Change on Asia's Growth 6

C. Asia's Economic Life Cycle: Consumption versus Labor Income 8

III. $\quad$ ESTIMATING POPULATION SURPLUS/DEFICIT 8

A. Working-Age Population $\quad 8$

B. Population Accounting: Estimating Workforce Deficit and Surplus 10

IV. $\quad$ WAYS TO AUGMENT THE LABOR FORCE 12

A. $\quad$ Extending the Retirement Age of Workers 12

B. Augmenting Labor Force through Increased Migration 16

C. Augmenting Labor Force by Increasing the Fertility Rate 21

$\begin{array}{lll}\text { V. CONCLUSION } & 24\end{array}$

$\begin{array}{lr}\text { APPENDIX } & 27\end{array}$

$\begin{array}{ll}\text { BIBLIOGRAPHY } & 37\end{array}$ 


\section{TABLES AND FIGURES}

\section{TABLES}

$1 \quad$ Workforce Population Accounting 3

2 Dependency Ratio: Total, Young, and Old (1950 versus 2050) 6

3 Potential Growth per Capita Estimated for 2015-2020: Developing Asia 6

$4 \quad$ Workforce Population, by Year 10

$5 \quad$ Workforce Population, by Economy 10

6 Aging Groups 11

$7 \quad$ Change in Population of Economies at Standard Dependency Ratio (Case 1) 18

$8 \quad$ Change in Population of Economies at Constant Dependency Ratio (Case 2) 20

A.1 Increase in Fertility Rate: Baseline (Case 1) versus Projected Fertility Rate (Case 2) 33

\section{FIGURES}

$1 \quad$ Age Structure in Asia, 1950-2050 3

2 Total Workforce in Asia 4

3 Dependency Ratio for Asia 5

$4 \quad$ Age Pyramids: Asia (2000, 2015, 2030, 2050) 9

5 Change in Population across Asia and the Pacific 11

6 Change in Population: Age Categories and Aging Stage 12

7 Labor Force Participation Rate 14

8 Dependency Ratios: Standard Retirement Age (65+) versus Extended Retirement Age (70+) 15

9 Dependency Ratios: Baseline (Case 1) versus Projected Fertility Rate (Case 2) 24

A.1 Workforce Population in Asia and the Pacific 27

A.2 Young, Old, and Total Dependency Ratios in Asia and the Pacific 29

A.3 Economic Life Cycle: Consumption versus Labor Income (Aggregate Levels) 31

A.4 Increase in Population: Baseline (Case 1) versus Projected Fertility Rate (Case 2)

(base year $=2010-2015$ ) 


\begin{abstract}
The world faces growing challenges of aging populations. Asia is no exception with rapidly increasing life expectancies and falling fertility rates. To help policy makers address these issues, this paper examines three sociopolicy options: (i) extending the retirement age, (ii) augmenting labor migration within the region, and (iii) through using population accounting methodology with the goal of increasing fertility rates. When the retirement age is extended from 65 to 70 , the overall dependency ratio in 2050 would decline from $56.7 \%$ to $44.7 \%$. If the 2010 dependency ratio were to be maintained, the region would need to import significant numbers of workers aged 15-44 even as those aged 45-64 would be in surplus. India, Pakistan, and the Philippines will be major sources of surplus labor. Raising fertility rates to the $2.1 \%$ replacement level will increase the dependency ratio for the time being, but will eventually reduce it over several decades depending on each country's demographic structure.
\end{abstract}

Keywords: demographic shift, dependency ratio, fertility rate, migration, population accounting

JEL codes: J11, J13, J61 


\section{INTRODUCTION}

World populations are aging-with the speed and extent of the demographic shift varying across developed and developing countries. The global phenomenon will become one of the most critical economic transformations of this century. It could propel the world toward a "new normal"-crosscutting the economic and social fabric of society-affecting everything from financial markets to family structures and intergenerational ties. To ensure sustainable development, policy makers need to deal with these demographic challenges.

Aging populations is not exclusively a developed country issue. A larger share of older populations now exists in developing countries, with a rate of growth significantly higher than in developed countries (United Nations 2013b). At the heart of this demographic shift lies Asia-not just with the largest share of the global population, but with the largest population of people aged 60 years or over. Based on the recently published 2015 Revision of World Population Prospects (United Nations 2015b), Asia had the highest global population share in 2015-at 60\%-and will continue to hold the highest share in 2050 (54\%). Of its total 2015 population, 508 million were over 60 years old-or 56\% of the global total. By 2050, the share will increase to 62\%, accounting for a projected 1.3 billion elderly. In less than half a century, Asia will be home to more than half the world's older population.

Asia's demographic shift held great significance. The so-called "East Asian Miracle"-which nearly tripled the subregion's real income per capita between 1965 and 1990-was set into motion because fertility rates began declining decades earlier. This marked the onset of the demographic shift (Bloom et al. 2000). In addition, rapid declines in infant and child mortality since the late 1940's helped trigger a fall in birth rates-from 40 births per 1,000 in 1950 to 20 per 1,000 by 1980 (Park and Shin 2011). In East Asia, the shift in age structure resulted in a working-age population growing between 1965 and 1990 nearly 10 times faster than the dependent population (Bloom et al. 2000). This paradigm shift propelled the subregion to rapid economic growth in the decades that followed.

Asia's prolonged economic expansion has been referred to in many studies as benefiting from the demographic dividend-the acceleration of economic growth associated with a rising share of working-age population to total population (ADB 2011). The UN 2013 National Transfer Accounts Manual refers to two stages of demographic dividend. The first demographic dividend occurs when an economy's output grows higher as the population share of its workforce becomes larger. The second wave of demographic dividend occurs as favorable changes in spending on human capital formation or savings and physical capital accumulation accompanies the rise in the workforce. East Asia's successful demographic and economic transformation is considered the best example of both the first and second demographic dividend. It demonstrates the ability of an economy to productively use its additional workers. In other words, East Asia's economies had the social (e.g. health and population), economic and political frameworks that allowed high savings and investment rates-amounting to almost three-quarters of the entire region's rates. Hence, along with the rapid expansion of the workforce, the subregion was able to rapidly accumulate physical capital and expand productive capacity.

However, the same demographic shift that propelled Asia's largest economies toward a rapid growth trajectory is coming to an end. It is posing different and growing challenges. Regional and global progress in health and population policies has created a growing number of elderly persons. Park and Shin (2011) estimated the region's demographic transition will have a substantial effect on economic growth over the next 2 decades, creating a demographic tax-the opposite of a demographic dividend. This continuing structural change in the region's demography poses challenges in terms of aggregate 
income, productivity, and economic activity. The main concern is the high and growing share of economically inactive retirees in the total population. A further concern is that, with the decline of fertility rates, labor supply will suffer, ultimately damaging the region's economic output. While demographic trends were conducive for economic growth in the past, they will be markedly less so in the future (ADB 2011).

But the structural change could catalyze a paradigm shift toward a new normal in labor force composition and for Asia's potential growth as well. Compared with the 1950's economic landscape, the region is uniquely characterized by factors far different from those the previous generation facedthe region's labor force is relatively mobile; women have higher labor force participation; and older persons are far better educated and tend to work beyond normal retirement. With the right demographic and social policies, these factors could provide an array of opportunities and channels to ensure sustainable growth at both country and regional levels.

This study offers a glimpse of how the demographic shift will frame Asia's future population structure-in particular the future working-age population and the resulting dependency ratio. Using population accounting methodology, it explains how effective certain policies could be in coping with the challenges associated with demographic change. The paper is structured in the following manner. Section II examines Asia's demographic changes and their economic impact. Section III provides estimations of population surplus and deficit by age and country group. Section IV investigates three options of augmenting the labor force: (i) extending the retirement age, (ii) increasing regional migration, and (iii) raising fertility rates. It analyzes how each option could help shore up shrinking working-age populations. Section $\vee$ concludes with policy recommendations.

\section{ASIA'S DEMOGRAPHIC CHANGE AND ECONOMIC IMPACT}

\section{A. Asia's Shifting Demographic Structure}

Data and forecasts show Asia's population and age structure have changed dramatically since 1950, and will continue to shift until at least mid century (Figure 1). Dependent youth (aged 0-14) crossed the 1 billion mark starting in 1990, falling below once again in 2005. Asia's working population (aged 15-64) is poised to reach its highest during 2040-2050. And those aged 65 and above are expected to total over 800 million beginning in 2045. As a share of world population, Asia's young dependent population (0-14) held the highest global share between 1962 and 1978; the working population (1564) share peaked starting 2002 and will continue to grow until 2024. And the elderly's (65+) share will continue to rise past 2050.

Asia's workforce by country-using UN population projections-show available labor in 12 economies will decline by varying magnitudes and timing. The 12 economies have a wide range of development and demographic structures (see Figure A.1). ${ }^{1}$ Seven will show a declining trend by 2050-the People's Republic of China (PRC); Japan; Hong Kong, China; the Republic of Korea; Singapore; Thailand, and Viet Nam. The rest-India, Indonesia, Malaysia, Pakistan, and the Philippines-will have an increasing workforce through 2050. The PRC-with the largest available workforce from 1950 until 2015-will be overtaken by India, with 1 billion by 2030 and more than 1.1 billion workers by 2050. Indonesia follows, rising continuously from 39.5 million in 1950 to 173 million in 2015 and 212 million by 2050. Japan's workforce reached 85 million in 1990, but has since declined

1 The 12 economies are included in Park and Shin 2011, excluding Taipei,China, but including Japan. 
and is estimated to drop to 55 million by 2050 . Thailand is also expected to drop from 49 million workers in 2015 to 36 million by 2050 (Table 1).

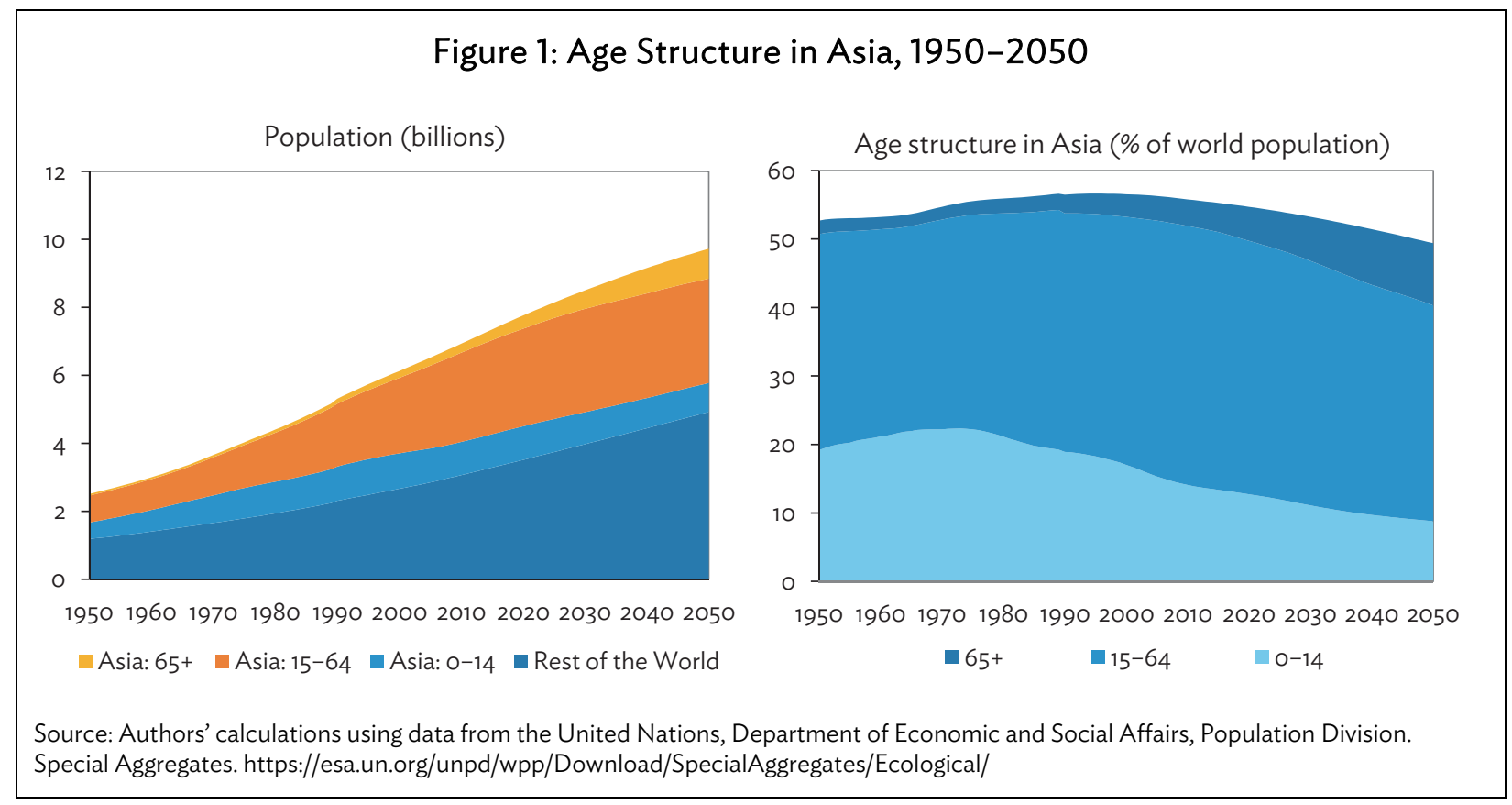

Table 1: Workforce Population Accounting (millions)

\begin{tabular}{l|rrrrr}
\hline \multirow{2}{*}{ Economies } & \multicolumn{5}{c}{ Workforce Population (15-64) } \\
\cline { 2 - 5 } & 1950 & 1990 & 2015 & 2030 & 2050 \\
\hline PRC & 332.9 & 759.9 & 1007.5 & 962.6 & 794.5 \\
Japan & 49.1 & 85.3 & 77.0 & 68.9 & 55.1 \\
Hong Kong, China & 1.3 & 4.0 & 5.3 & 4.8 & 4.4 \\
India & 223.4 & 507.0 & 860.0 & 1033.3 & 1144.6 \\
Indonesia & 39.5 & 108.5 & 172.9 & 201.1 & 212.5 \\
Republic of Korea & 10.5 & 29.8 & 36.7 & 33.1 & 27.0 \\
Malaysia & 3.3 & 10.8 & 21.1 & 24.7 & 27.0 \\
Pakistan & 20.3 & 57.1 & 114.3 & 156.3 & 206.2 \\
Philippines & 9.8 & 34.6 & 63.9 & 80.3 & 98.8 \\
Singapore & 0.6 & 2.2 & 4.1 & 4.1 & 3.7 \\
Thailand & 11.3 & 36.9 & 48.8 & 45.4 & 35.7 \\
Viet Nam & 15.9 & 38.8 & 65.6 & 71.0 & 69.6 \\
\hline Total & 718.0 & $1,675.0$ & $2,477.1$ & $2,685.8$ & $2,679.1$ \\
\hline
\end{tabular}

PRC=People's Republic of China.

Source: Authors' calculations using data from the United Nations, Department of Economic and Social Affairs, Population Division. Special Aggregates. https://esa.un.org/unpd/wpp/Download/SpecialAggregates/Ecological/ 
However, the aggregate workforce in Asia will retain its demographic dividend until the middle of the century. The total workforce of the 12 major Asian economies shows an increasing trend through 2030-from 2.5 billion in 2015 to 2.7 billion in 2030. And if we account for all 48 Asian economies, the region will continue to see an increase in its workforce through the middle of the century (Figure 2)-from 2.8 billion in 2015 to 3.03 billion in 2030 and 3.06 billion in 2050.

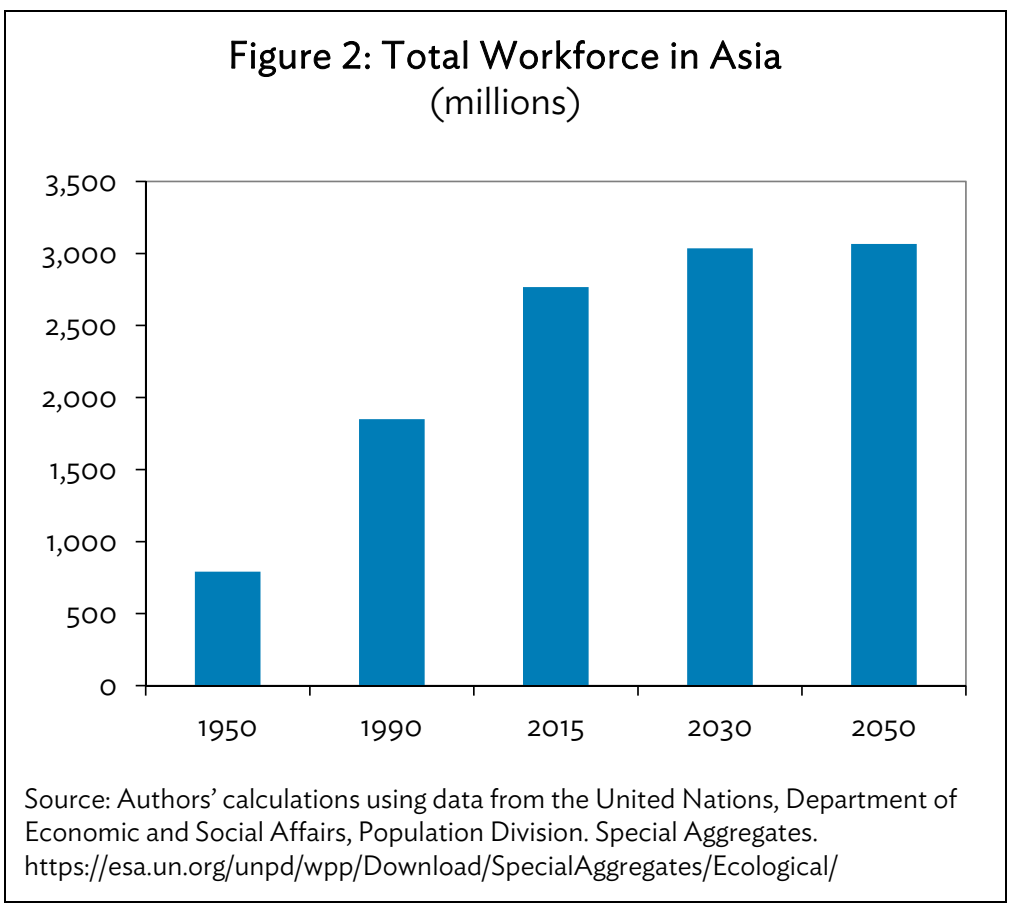

As the region ages, traditional measures used in demographic analysis-such as dependency ratios-would be expected to change. The dependency ratio is a static measure of the effect demographic factors exert on standards of living. In particular, the ratio gives a picture of an economy's "dependent" population that relies on the working population for financial support-via family transfers or public transfer programs. These dependents are composed of children, youth, and retirees assumed not to contribute to an economy's production. Thus, the dependency ratio reflects the relationship between two segments of the population: the number of pure consumers and the number of those who also produce (Kleiman 1967).

In this paper, the total dependency ratio is the ratio of the sum of the young dependent population (0-14) and old dependent population (65+) to the working-age population (15-64). Asia's total dependency ratio averaged 78\% in 1960s, falling to a low of 47\% in 2013 and 2014. Forecasts show the ratio will increase to $57 \%$ by 2050 (Figure 3). There are two trends at play: (i) the rapid increase in the elderly population and (ii) the sluggish increase in working-age people. The old age dependency ratio (ratio of the elderly to working-age population) has rapidly grown from $6 \%$ in 1950 to $11 \%$ in 2015 and could reach $29 \%$ in 2050. 


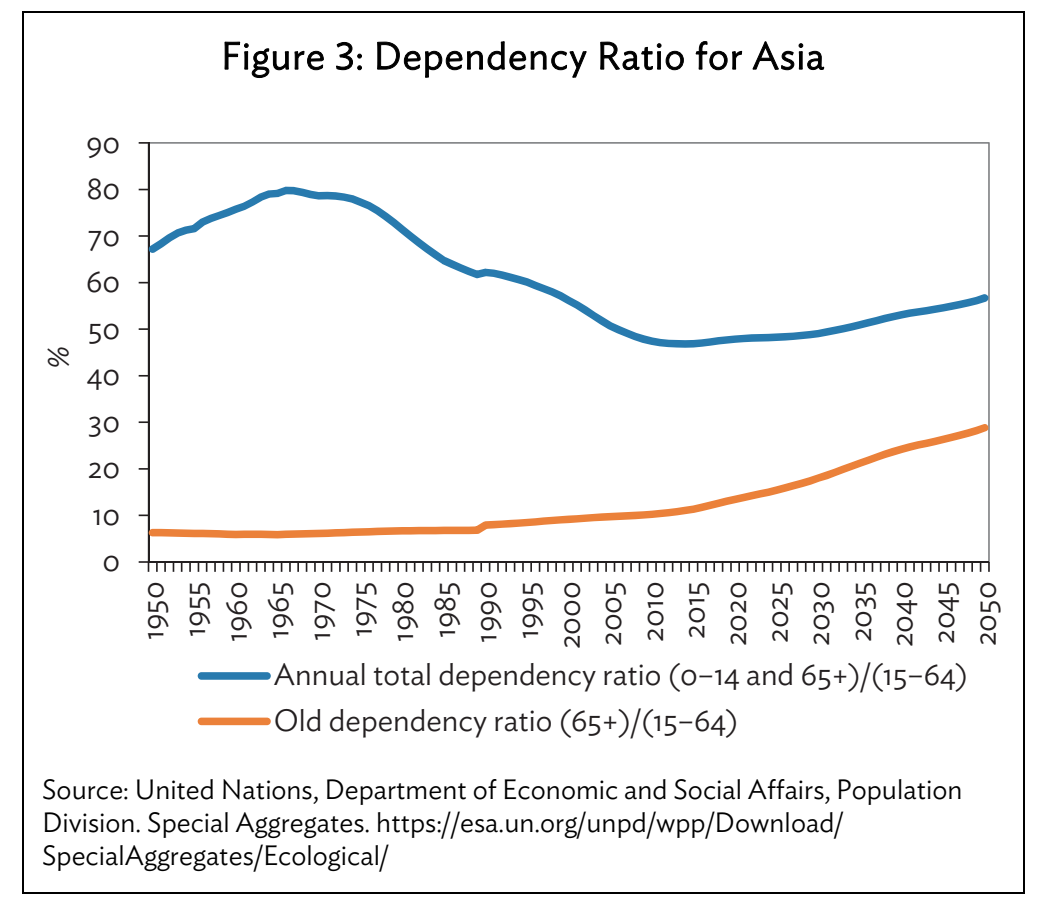

The magnitude and timing of aging will differ across economies. Country-level data shows varying trends of total dependency across the region as changes in the proportion of children, the elderly, and the workforce vary. In the analysis, dependency ratios (total, youth, and elderly) of 12 Asian economies showed a relatively aging demographic structure that reached its lowest total dependency ratios between 2000 and 2015 (Figure A.2). The exception is Japan, which reached its 43\% dependency ratio in 1992. Hong Kong, China and the PRC hit their lows in 2009 with 33\% (the lowest of the 12 economies) and 35\% total dependency ratio, respectively. This was followed closely by Singapore in 2010 (36\%) and Thailand in 2012 (39\%). The Republic of Korea (37\%) and Viet Nam (42\%) hit their lows in 2013. In 2019, Malaysia is forecast to reach its lowest dependency ratio (43\%) followed by Indonesia (47\%) in 2030. Of the 12 economies, only two-the Philippines and Pakistanare not forecast to bottom out through 2050.

The 10 economies which already passed their lowest dependency ratios are now seeing gradually increasing dependency ratios. Japan stands out with the highest projected dependency ratio by 2050-a staggering 95\% - followed by Hong Kong, China and the Republic of Korea (87\%) by the middle of the century. Singapore and Thailand will reach $82 \%$ and $75 \%$, respectively (Table 2 ).

The two components of dependency ratio-the young and old-show similar trends in Japan; the PRC; Hong Kong, China; the Republic of Korea; Singapore; Thailand; and Viet Nam. As the old dependency ratios in these eight countries begin to rise, the dependency ratios for children and youth decline significantly, crossing the elderly component (Figure A.2). Between 2015 and 2050, Japan should reach its highest old dependency ratio (71\%) in 2050 from 43\% in 2015. The Republic of Korea comes second (66\%) in 2050 from 18\% in 2015 followed by Hong Kong, China (65\% in 2050 from 21\% in 2015). Dependency ratios for the young show decreasing trends-reflecting declining fertility rates. Singapore reports the lowest ratio (20\% in 2050 from 21\% in 2015). The Republic of Korea comes second (21\% in 2050 from 19\% in 2015) (Table 2). Overall, the total dependency ratio is forecast to rise between 2015 and 2050 in all Asian economies except India, Pakistan, and the Philippines. 
Table 2: Dependency Ratio: Total, Young, and Old (1950 versus 2050)

\begin{tabular}{l|c|c|c|c|c|c}
\hline \multirow{2}{*}{} & \multicolumn{2}{|c|}{$\begin{array}{c}\text { Total Dependency Ratio } \\
{[(0-14)+(65+) /(15-64)]^{*} 100}\end{array}$} & \multicolumn{2}{c|}{$\begin{array}{c}\text { Young Dependency Ratio } \\
{[(0-14) /(15-64)]^{*} 100}\end{array}$} & \multicolumn{2}{c}{$\begin{array}{c}\text { Old Dependency Ratio } \\
{[(65+) /(15-64)]^{*} 100}\end{array}$} \\
\cline { 2 - 7 } & 2015 & 2050 & 2015 & 2050 & 2015 & 2050 \\
\hline PRC & 36.6 & 69.7 & 23.5 & 22.9 & 13.0 & 46.7 \\
Japan & 64.5 & 95.1 & 21.1 & 24.3 & 43.3 & 70.9 \\
Hong Kong, China & 37.0 & 87.1 & 16.4 & 22.5 & 20.6 & 64.6 \\
India & 52.4 & 49.0 & 43.9 & 28.5 & 8.6 & 20.5 \\
Indonesia & 49.0 & 51.6 & 41.2 & 30.3 & 7.7 & 21.3 \\
Republic of Korea & 37.2 & 87.2 & 19.2 & 21.4 & 18.0 & 65.8 \\
Malaysia & 43.6 & 50.8 & 35.2 & 25.4 & 8.4 & 25.3 \\
Pakistan & 65.3 & 50.2 & 57.9 & 37.5 & 7.4 & 12.7 \\
Philippines & 57.6 & 50.1 & 50.3 & 35.6 & 7.2 & 14.5 \\
Singapore & 37.4 & 81.6 & 21.4 & 20.0 & 16.1 & 61.6 \\
Thailand & 39.2 & 74.7 & 24.7 & 22.2 & 14.6 & 52.5 \\
Viet Nam & 42.5 & 62.0 & 32.9 & 27.9 & 9.6 & 34.1 \\
\hline
\end{tabular}

PRC = People's Republic of China.

Source: Authors' calculations using data from the United Nations, Department of Economic and Social Affairs, Population Division. Special Aggregates. https://esa.un.org/unpd/wpp/Download/SpecialAggregates/Ecological/

\section{B. Impact of Demographic Change on Asia's Growth}

ADB's latest Asian Development Outlook highlighted developing Asia's fading demographic dividend as a major factor in the region's shift to a "new normal" for potential growth (ADB 2016). ${ }^{2}$ It said that average population growth is expected to be lower in 2015-2020 than in 2008-2014 in all Asian developing economies (with the exception of Sri Lanka). Using an estimated average potential growth rate and actual population growth for 2008-2014, results indicate that average potential growth per capita in 2015-2020 will be between $5.31 \%$ and $5.72 \%$ (Table 3). Thus, potential growth per capita in developing Asia is expected to fall relative to 2008-2014 by an average of 0.17-0.58 percentage points annually. The report states this is because the fall in working-age population growth over the period becomes greater than the fall in total population growth. Figure 2 shows that beginning 2015 , growth in working-age population is $0.9 \%$ - below the $1.0 \%$ growth in total population. By 2050 , working-age population growth will decline to $-0.2 \%$, well below the $0.1 \%$ growth in total population.

Table 3: Potential Growth per Capita Estimated for 2015-2020: Developing Asia

(\%)

\begin{tabular}{ll}
\hline Potential growth per capita in 2008-2014 & 5.89 \\
\hline Potential growth per capita in 2015-2020a & 5.72 \\
\hline Potential growth per capita in 2015-2020 & 5.31 \\
\hline a Based on 2008-2014 average. \\
b Based on the 2014 estimate. \\
Source: ADB. 2016. Asian Development Outlook 2016: Asia's Potential Growth. Manila.
\end{tabular}

2 Developing Asia excludes Japan, Australia, and New Zealand. 
Park and Shin (2011) estimate the impact the demographic transition has on developing Asia's past and future growth trajectories. Essentially, the report builds on the hypotheses that an increasing population share of workers translates into a higher per capita growth path. The study cites four factors by which changes in the population age structure affect economic growth: (i) the workforce population, (ii) savings, (iii) physical capital accumulation, and (iv) total factor productivity (TFP). The principle behind workforce population and savings factors draws on the economic life cycle theory (discussed later in the report) which states that working-age adults tend to work and save more than their dependent counterparts (youth and the elderly). This translates into lower consumption per currency unit of labor income for working-age adults and higher consumption per currency unit of labor income for youth and the elderly. In aggregate, economies with high working-age populations and small dependent populations create a higher growth path for per capita output and, consequently, a higher propensity to save. Meanwhile, the principle of physical capital accumulation involves two competing theories. First, if physical capital and labor are substitutes, then capital accumulation could replace the declining share of labor due to the increasing share of elderly workers (with diminished or deteriorating physical capacity). The second competing theory is if the two components are complementary, then the growth effect of physical capital accumulation may not be as strong, given a declining labor force share. Finally, the TFP improvements may stem from a demographic change in the economy (such as the higher tendency of youth to adapt to innovation) which, in turn, could lead to an increase in growth rates of output per capita.

To represent the demographic shift in developing Asia, the authors use estimates of dependency ratios for the elderly (aged 65 and above) and youth (aged 0-14) to measure their effect on the four channels of economic growth. In the study, 12 major developing Asian economies were analyzed: the PRC; Hong Kong, China; India; Indonesia; the Republic of Korea; Malaysia; Pakistan; the Philippines; Singapore; Taipei,China; Thailand; and Viet Nam. They represent a wide range of development and demographic structures. Youth dependency ratios are expected to decline from 1981 to 2030, while the dependency ratios for the elderly are expected to increase over the same period. The quantitative estimates of past and forecast demographic dividends show that the combined effect of the change in the youth dependency ratio on the four growth channels vary across sample economies from 1981 to 2030. For the PRC; Hong Kong, China; and Thailand, there is a declining trend in the percentage point contribution to gross domestic product (GDP) per capita growth from 19811990 to 2021-2030. In particular, Thailand shows the largest decline in the estimates across time periods - from an increase of 2.5\% of GDP per capita growth in 1981-1990 to just $0.074 \%$ in 2021 2030. Hong Kong, China shows a negative 0.26\% impact in 2021-2030 from 1.5\% in 1981-1990. Similarly, Singapore shows a negative 0.11\% impact in 2021-2030 from 1.9\% in 1981-1990. The trends for the other eight economies fluctuate, mostly positive but with lesser impact. The results clearly underscore the theory that the contribution of demographic changes to developing Asia's growth will decline substantially as the region's population ages.

However, the combined effect of changes in dependency ratios for the elderly shows a negative and increasing trend in six economies from 1981 to 2030-the PRC; Indonesia; the Republic of Korea; the Philippines; Singapore; and Thailand. Singapore is forecast to have the largest negative impact of $2.4 \%$ on its GDP per capita growth in $2021-2030$ from $-0.14 \%$ in 1981-1990. Hong Kong, China comes next with a $-1.9 \%$ contribution to annual GDP per capita growth in 2021-2030 from $-0.4 \%$ in $1981-1990$. The Republic of Korea shows a $-1.5 \%$ contribution to annual GDP per capita growth by $2021-2030$ from $-0.09 \%$ impact in 1981-1990. 


\section{Asia's Economic Life Cycle: Consumption versus Labor Income}

Apart from the traditional measure of dependency ratios, an alternative measure has been pioneered by the National Transfer of Accounts of the Department of Economic and Social Affairs of the United Nations Secretariat. It uses the life cycle pattern of consumption to capture the significance of a population's age structure in aggregate. Simply put, the gaps between consumption and labor income-or the life cycle deficit-should be reallocated from the working-age population. In young populations, the aggregate economic life cycle is characterized by prolonged periods of deficit, wherein consumption surpasses production. In the working-age population, we observe life cycle surpluses because this age group contributes to the economy's production through labor. Deficits and surpluses are only sustainable given a system of institutions and economic mechanisms that enable economic resources to flow from surplus to deficit ages (United Nations 2013a).

The life cycle also measures the propensity of a demographic structure to save, thus giving a picture of an economy's second wave of demographic dividends. According to the life cycle hypotheses model, working-age people tend to save more when young and drawdown savings as they approach retirement (World Bank 2016). This means that for an aging economy, the savings rate will decline as more and more individuals approach the old age bracket.

At the aggregate level, we see consumption is higher than labor income in the young dependent age group (0-20 years) with labor income higher as the population reaches working age. In general, surpluses tend to emerge as the age bracket moves above 20 years and deficits reappear as the trend reaches 50 years or higher. However, consumption increases as the population reaches 90 years and above, especially in developed countries such as the United States, Japan, and Germany. The Republic of Korea and India also show an observable jump, though not as high as the three developed countries. (see Figure A.3).

Population aging could pose risks to economic growth as the effective number of workers contributing to total labor income declines relative to the effective number of consumers. The challenge for policy makers in aging societies is to find ways to compensate for the rapid consumption increase amid declining labor income as the middle of the century approaches.

\section{ESTIMATING POPULATION SURPLUS/DEFICIT}

\section{A. Working-Age Population}

Asia's demographic transition is in part an acceleration of population aging. At the root of the shift is an exceptionally rapid increase in the number of elderly arising from the high birth rates during the early and middle 20th century. Rapid improvements in life expectancy-due to better health and disease prevention-also contributed to expanding older populations. The UN World Populations Prospects 2015 (United Nations 2015b) confirms that, globally, life expectancy at birth rose by 3 years between 2000-2005 and 2010-2015-from 67 to 70 years. By 2045-2050, life expectancy should increase to 77 years and will reach 83 years in 2095-2100. In Asia, life expectancy was 72 years in 2010-2015 and is projected to jump to $85-86$ years by $2095-2100 .^{3}$

3 Based on UN World Population Prospects: The 2015 Revision: Key Findings and Advance Tables. 
The number of elderly (65+ years old) in the region increased from 50 million in 1950 to 203 million in 2000, and will continue its rapid increase to just below 900 million in 2050-almost 5 times the 2000 level.

The proportion of the population aged 65 or over will increase from 3.3\% to $5.6 \%$ between 2000 and 2025-an increase of 2.3 percentage points. This will accelerate to a 5.8 percentage point increase by 2050 , for an old age population share of $9.1 \%$. The age pyramids below illustrates the region's demographic transformation within the span of half a century (Figure 4). From the wide young population base in 2000, Asia will rapidly shift to a more rectangular shape of an older population by 2050. Based on the 2050 figure, the age group with the highest share of total population will be from 30 to 39 followed by 55 to 64 .

As discussed in the previous section, the workforce population in Asia by 2050 will still expand. However, due to declining fertility rates, the speed of expansion has been slowing since 1990. Asia's workforce reached its highest growth rate of 29\% (10-year growth) in 1990, but has since been declining-down to $18 \%$ in 2010, $6 \%$ in 2030 and finally forecast to post negative growth of $0.4 \%$ by 2050 (Table 4). By economy, Japan posted negative growth of 5\% in 2010-the earliest of the 12 major economies. Two economies are projected to join Japan in posting negative working population growth in 2020-the PRC at $-0.4 \%$ and Hong Kong, China at $-1.1 \%$. By 2030 , three more countries will have negative growth - the Republic of Korea, Singapore, and Thailand (Table 5).

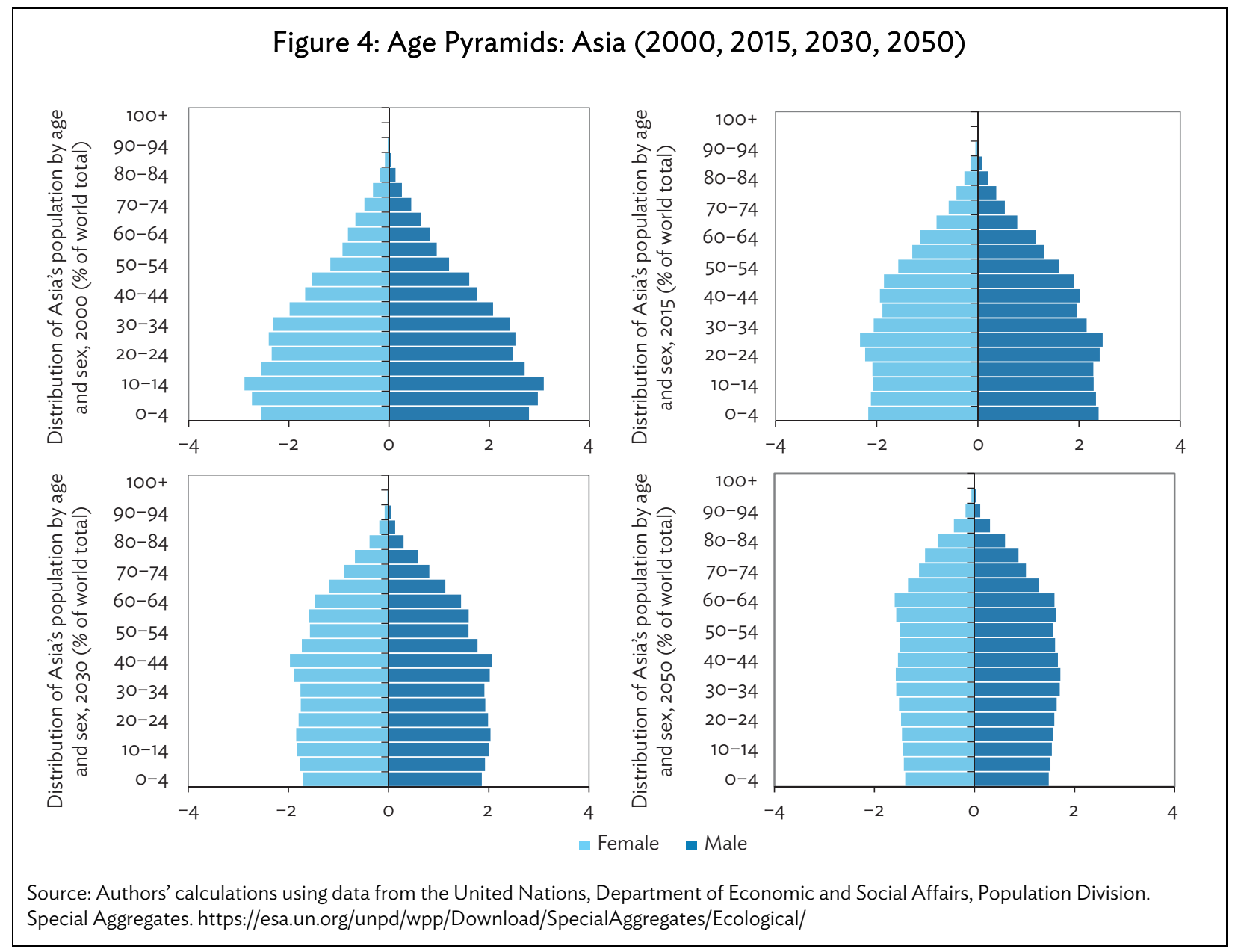


Table 4: Workforce Population, by Year

(\% growth rate, decade-on-decade)

\begin{tabular}{c|c|c}
\hline \multirow{2}{*}{} & \multicolumn{2}{|c}{ Workforce Population (15-64): Asia } \\
\cline { 2 - 3 } & millions & \% growth \\
\hline 1960 & 908 & 14.8 \\
1970 & 1120 & 23.3 \\
1980 & 1436 & 28.2 \\
1990 & 1850 & 28.8 \\
2000 & 2219 & 20.0 \\
2010 & 2623 & 18.2 \\
2020 & 2871 & 9.5 \\
2030 & 3036 & 5.8 \\
2040 & 3077 & 1.3 \\
2050 & 3066 & -0.4 \\
\hline
\end{tabular}

Source: Authors' calculations using data from the United Nations,

Department of Economic and Social Affairs, Population Division. Special Aggregates.

https://esa.un.org/unpd/wpp/Download/SpecialAggregates/Ecological/

Table 5: Workforce Population, by Economy

(\% growth rate, decade-on-decade)

\begin{tabular}{|c|c|c|c|c|c|c|c|c|c|c|}
\hline \multirow{2}{*}{ Economies } & \multicolumn{10}{|c|}{ Working Population } \\
\hline & 1960 & 1970 & 1980 & 1990 & 2000 & 2010 & 2020 & 2030 & 2040 & 2050 \\
\hline PRC & 9.2 & 23.8 & 28.9 & 31.0 & 14.1 & 15.0 & -0.4 & -3.1 & -10.0 & -8.3 \\
\hline Japan & 20.9 & 20.4 & 9.4 & 9.1 & 0.6 & -5.3 & -9.2 & -6.5 & -11.5 & -9.7 \\
\hline Hong Kong, China & 30.6 & 34.9 & 48.7 & 16.5 & 20.4 & 7.7 & -1.1 & -7.8 & -3.9 & -5.3 \\
\hline India & 14.0 & 21.4 & 28.8 & 27.3 & 26.5 & 22.9 & 17.5 & 11.6 & 7.5 & 3.1 \\
\hline Indonesia & 25.5 & 23.7 & 32.9 & 32.9 & 26.0 & 17.0 & 15.4 & 9.0 & 4.4 & 1.2 \\
\hline Republic of Korea & 32.2 & 23.6 & 35.9 & 28.0 & 11.1 & 7.7 & 1.8 & -8.7 & -10.4 & -9.0 \\
\hline Malaysia & 26.2 & 35.9 & 40.2 & 35.9 & 36.3 & 29.6 & 18.9 & 8.9 & 7.4 & 1.8 \\
\hline Pakistan & 25.0 & 23.1 & 33.0 & 37.4 & 32.6 & 33.3 & 26.1 & 22.8 & 18.2 & 11.6 \\
\hline Philippines & 33.6 & 39.3 & 39.3 & 36.2 & 31.1 & 27.5 & 20.1 & 15.5 & 12.5 & 9.4 \\
\hline Singapore & 53.1 & 34.3 & 37.2 & 33.6 & 26.8 & 34.1 & 13.4 & -3.2 & -5.4 & -5.2 \\
\hline Thailand & 30.7 & 31.0 & 39.0 & 37.2 & 17.9 & 10.1 & 1.1 & -6.2 & -11.0 & -11.7 \\
\hline Viet Nam & 13.6 & 22.5 & 32.6 & 32.6 & 28.1 & 24.0 & 9.9 & 4.8 & 1.5 & -3.4 \\
\hline
\end{tabular}

PRC = People's Republic of China.

Source: Authors' calculations using data from the United Nations, Department of Economic and Social Affairs, Population Division. Special Aggregates. https://esa.un.org/unpd/wpp/Download/SpecialAggregates/Ecological/

\section{B. Population Accounting: Estimating Workforce Deficit and Surplus}

This section presents Asia's demographic shift across varying age groups: 0-14, 15-29, 30-44, 45-64, and 65+. The study groups economies in Asia based on the percentage of the population aged 65+ or over by 2030 . The early stage represents economies with $0 \%-10 \%$ of the population aged 65 or over; the middle stage represents economies having $11 \%-20 \%$ of the population aged 65 or over; and advanced stage represents economies with over 21\% of the population aged 65 or over by 2030 (Table 6). Figure 5 illustrates the deficits and surpluses across age categories and aging stages using 2010 as the baseline scenario. We observe the apparent transition toward an older population given the huge deficits in young populations (from 0-14 to 15-29), while the older working population (ages 30-44 and 45-64), and the elderly (age 65 and above), continue to post surpluses until 2050. In particular, the young dependent population ages 0-14 hold very low surpluses in 2015 through 2020, reversing into deficit starting 2025 up to 2050. Meanwhile, there are deficits within the 15-29 age range from 2015 to 2050. In contrast, surpluses appear for ages 30-65+ until 2050 with the population aged 45 and 64 years posting the 
highest surplus among the workforce population. The $65+$ age range posts the highest surplus starting 2040 until 2050 - consistent with data on the share of old population.

\section{Table 6: Aging Groups}

\begin{tabular}{l|l}
\hline Early stage (0\%-10\%) & $\begin{array}{l}\text { Afghanistan, Bangladesh, Bhutan, Cambodia, Cook Islands, Fiji, India, } \\
\text { Indonesia, Kiribati, Kyrgyz Republic, Lao People's Democratic }\end{array}$ \\
& Republic, Malaysia, Maldives, Marshall Islands, Federated States of \\
& Micronesia, Mongolia, Myanmar, Nauru, Nepal, Pakistan, Palau, Papua \\
& New Guinea, Philippines, Samoa, Solomon Islands, Tajikistan, Timor- \\
& Leste, Tonga, Turkmenistan, Tuvalu, Uzbekistan, Vanuatu \\
\hline Middle stage (11\%-20\%) & $\begin{array}{l}\text { Armenia, Australia, Azerbaijan, Brunei Darussalam, People’s Republic } \\
\text { of China, Georgia, Kazakhstan, Sri Lanka, Thailand, Viet Nam }\end{array}$ \\
\hline Advanced stage (21\% and above) & Hong Kong, China; Japan; Republic of Korea; New Zealand; Singapore \\
\hline
\end{tabular}

Note: Based on the percent of the population aged 65 and above by 2030.

Source: Authors' assumptions.

Figure 6 shows the overall breakdown in surpluses/deficits in population based on aging stage. Economies at the advanced aging stage hold overall deficits from 2015 up to 2050 for populations aged $0-14,15-29$, and 30-44 years, but posts total surpluses for the population aged 65 and above. However, given that only five Asian economies belong to the advanced aging stage, the magnitude of these surpluses and deficits are relatively small compared with the overall magnitude of those economies in the middle and early stages. In contrast, economies in the middle aging stage-including the PRC - hold huge overall deficits from 2015 to 2050 for the populations aged 0-14, 15-29, and 3044 years. Further, these economies post high surpluses for the population aged 45-64 and ultimately gain the highest surpluses for those aged 65 and above. On the contrary, economies at the early stage show surpluses for populations aged 15-29, 30-44, 45-64, and 65 and above from 2015 to 2050. Its surpluses peak for the population aged 45 to 64 years. Notably, Figure 7 indicates very large surpluses across all economies for the population ages 45-64 and 65+ from 2015 to 2050-reflecting the accumulation of elderly workers and the old dependent population. The results of this population accounting show the working-age group remains dominant across the region. However, we clearly see declining fertility and the accumulation of the elderly population from 2015 to 2050.

Figure 5: Change in Population across Asia and the Pacific (base year $=2010$ )

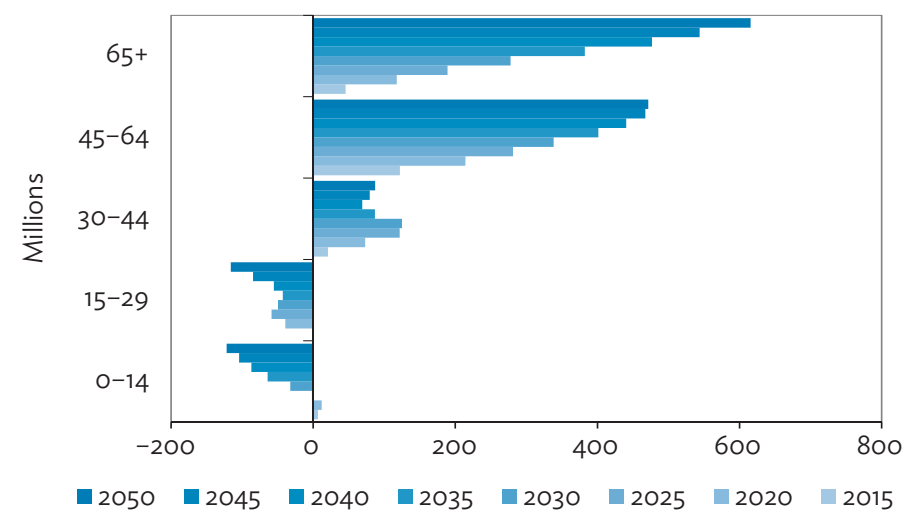

Source: Authors' calculations using data from the United Nations, Department of Economic and Social Affairs, Population Division. Special Aggregates. https://esa.un.org/unpd/wpp/Download/SpecialAggregates/Ecological/ 


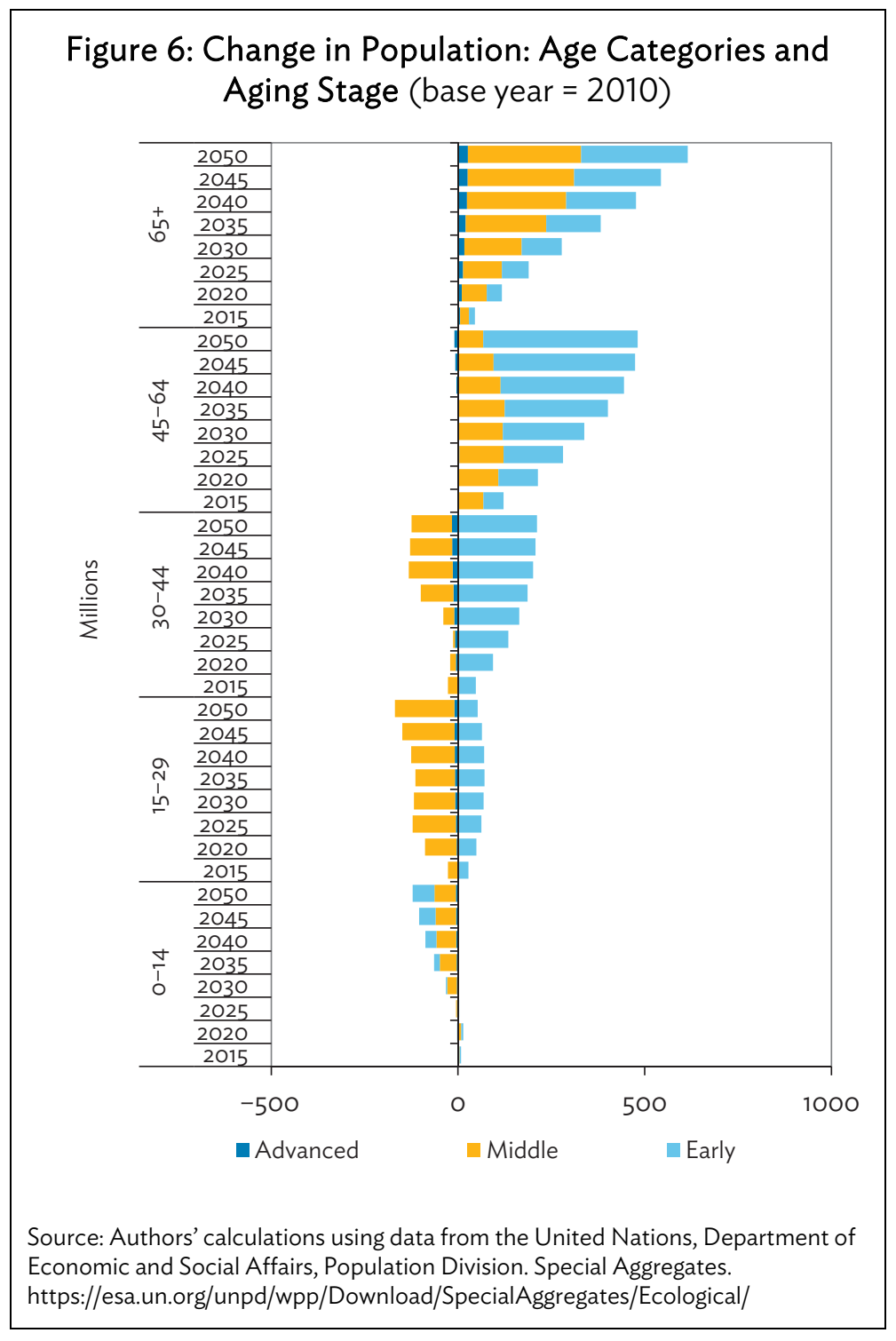

\section{WAYS TO AUGMENT THE LABOR FORCE}

Boosting workforce participation can shore up the shrinking traditional labor pool due to population aging in Asia. Here we discuss three ways to augment the labor force in aging economies using a simulation framework based on simple assumptions of retirement age, migration, and fertility rates.

\section{A. Extending the Retirement Age of Workers}

Policy makers are increasingly concerned that as the labor force ages, productivity will decline-an elderly workforce is generally less productive than a younger one. However, there is evidence of the opposite trend-especially in developed countries where older workers have better education, better health, and lower mortality. This questions the traditional, widely accepted paradigm and offers an 
alternative view that as the workforce ages, it accumulates experience that ultimately translates to higher earnings and productivity.

Burtless (2013) finds little evidence that the rising importance of older workers in the United States has hurt average productivity. He notes that, unlike the prebaby boomer generation, those currently aged 60-70 are very well educated compared with past generations of elderly men and women with considerably less schooling. The study reports that, using a standard measure of worker productivity, workers between 60 and 74 are more productive than the average younger worker. This may be because less productive workers leave the workforce at younger ages, while older workers that tend to stay in the workforce compare favorably in average productivity.

Another study says the many negative associations with older employees in Germany result from correlations between elderly employees and other characteristics that bias perceptions of performance. These include (i) being less educated on average, (ii) belonging to a less productive cohort that previously worked without modern technological tools, and (iii) working in sunset industries and establishments. However, when these characteristics are accounted for in addition to age, the relationship between age and performance tends to be more positive-the perception of a negative effect on performance vanishes (Zwick et al. 2013). The takeaways of the study are that (i) elderly employees on average are just as productive as younger employees; despite large variances between enterprises and (ii) applying age-specific workplaces, specific jobs for old employees and mixed-age working teams is associated with significantly higher relative productivity of older employees, among others.

A recently published World Bank report (World Bank 2016) on population aging supports this in regards to East Asia. Those in more developed economies such as Japan; the Republic of Korea; Singapore; and Hong Kong, China tend to study longer and start work later. The report cites East Asian surveys that indicate workers stay in the labor force longer given economic incentives and strong social engagement. In a survey among Japanese respondents aged 60 and over, 36.8\% of respondents indicate the desirability to work as long as they are able, $23 \%$ are willing to work until age 70, while $8.9 \%$ want to work until age 75. At present, based on Organisation for Economic Co-operation and Development figures, the expected retirement age in Japan is 65 for both men and women. Similarly, the Republic of Korea; Hong Kong, China; and the Philippines peg retirement at 65 years for both men and women. Meanwhile, the expected retirement in the PRC and Viet Nam for men is 60 years and 55 years for women. India, Malaysia, and Thailand have normal pension eligibility for both men and women at 55 years.

This trend is supported in Figure 7 which forecasts labor force participation in Asia from 2033 to 2050 of the workforce aged 60-64 and 65+ (against the total labor force aged 15 to 74 years old). The labor force estimates are based on International Labour Organization projections, while population forecasts are taken from the United Nations, Department of Economic and Social Affairs, Population Division database. The figure shows that the increase in the labor force participation rate is forecast to be much greater for those aged 65 and above. While the workforce aged 60-64 will increase by 0.8 percentage points from 2033 to 2050, the workforce aged 65+ will increase by 2 percentage points. A similar trend is seen in Japan, the PRC, and the Republic of Korea. Across these three countries, the workforce aged 65 and above is expected to have a higher labor force participation rate from 2033 to 2050 . 


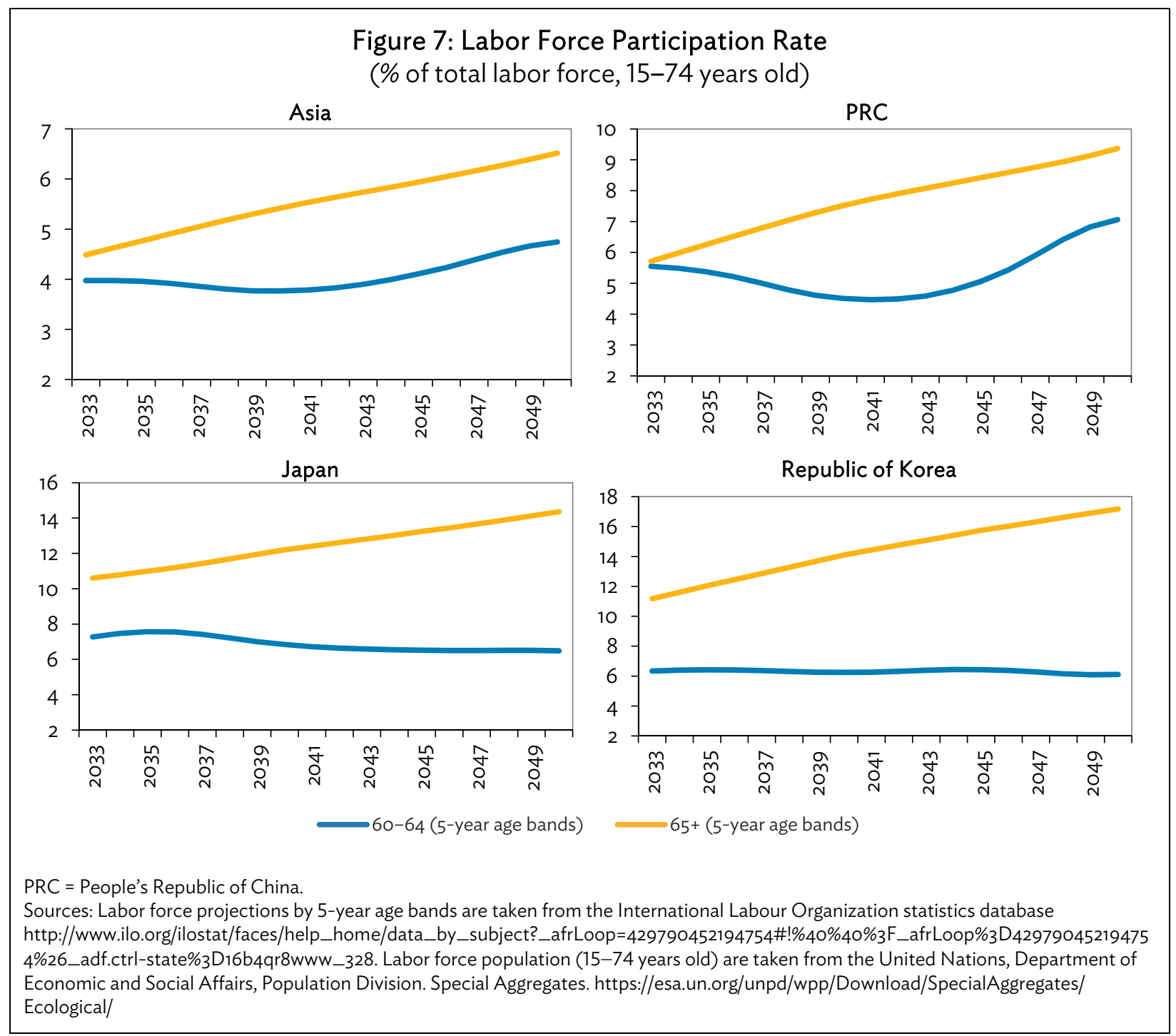

Following this hypothesis and given the growing role the elderly play in Asia and the Pacific, we compare two trends of the region's total dependency ratio based on two scenarios given by the simple equation below: (1) if we maintain retirement age at 65 and above, and (2) if we extend retirement to 70 years and above.

$$
\begin{aligned}
& \text { Total dependency ratio }(A)=\frac{P_{0-14}+P_{65+}}{P_{15-64}} \\
& \text { Total dependency ratio }(B)=\frac{P_{0-14}+P_{70+}}{P_{15-69}}
\end{aligned}
$$

where, $P_{0-14}=$ estimate for the young dependent population aged $0-14$ years old

$P_{65+}=$ estimate for the old dependent population aged 65 and above

$P_{70+}=$ estimate for the old dependent population aged 70 and above

$P_{15-64}=$ estimate for the working population aged 15-64 years old

$P_{15-69}=$ estimate for the working population aged 15-69 years old 
The results show a significant decline in the total dependency ratio when the retirement age is extended (Figure 8). By 2050, Asia's total dependency ratio at extended retirement age is significantly lower at $44.7 \%$ compared with a $56.7 \%$ dependency ratio at the standard retirement age. This accounts for a $12 \%$ difference between the two in 2050. In the case of Japan, the dependency ratio at standard retirement age will accelerate to $95.1 \%$ in 2050 from $64.5 \%$ in 2015, while the dependency ratio at extended retirement age will moderate to $73.1 \%$ in 2050 . Meanwhile, the dependency ratio in the Republic of Korea is $87.2 \%$ by 2050 (at standard retirement age) from 37.2\% in 2015, but could moderate to $65.4 \%$ in 2050 with extended retirement. Similarly, Hong Kong, China posts an $87.1 \%$ ratio at standard retirement age by 2050 , but would likely decline to $66 \%$ at extended retirement age. As expected, the aging economies in East Asia account for the highest difference between the two ratios by $2050-22 \%$ in Japan and the Republic of Korea and 21\% in Hong Kong, China.

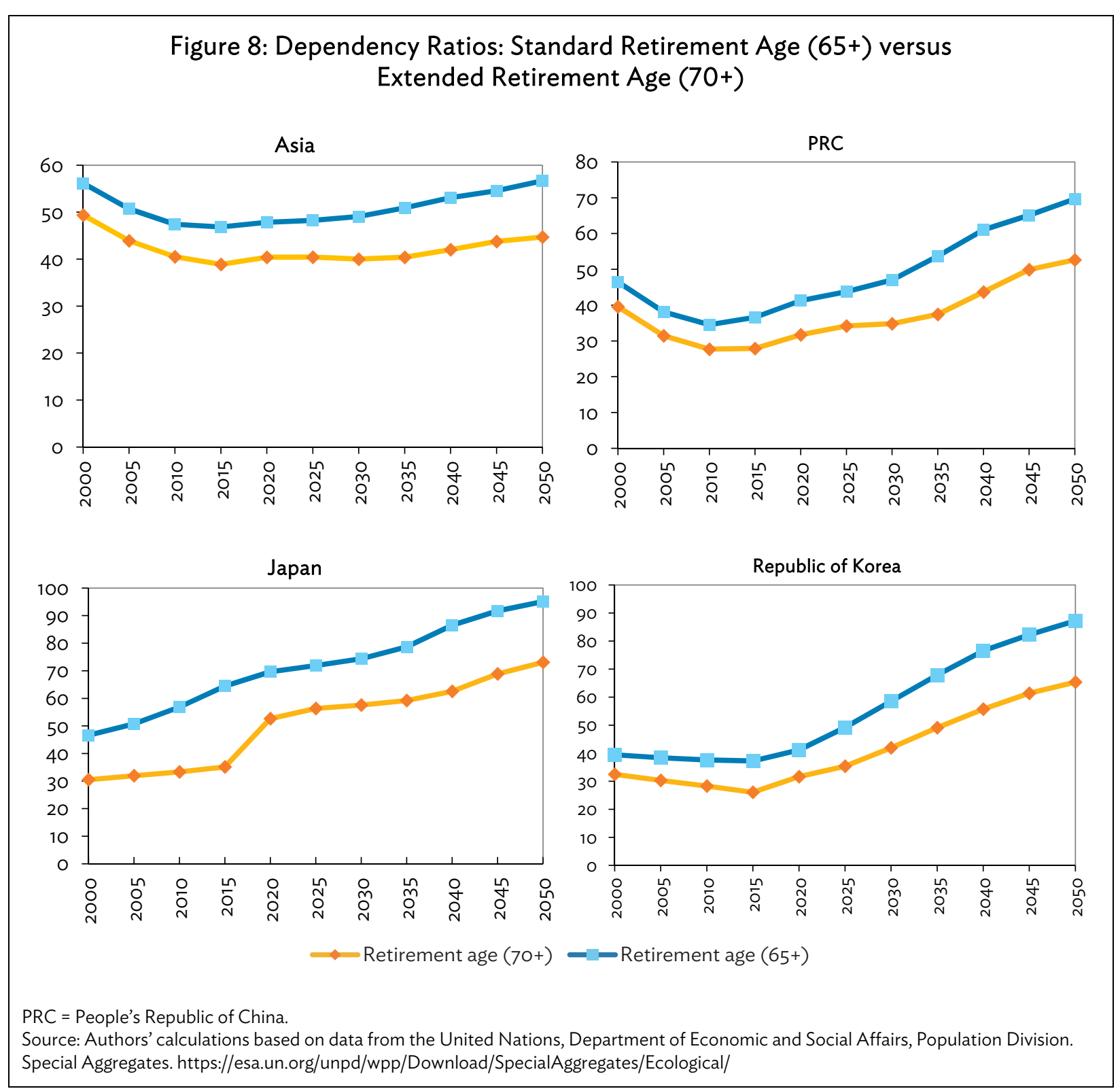




\section{B. Augmenting Labor Force through Increased Migration}

An increase in migration could help augment the labor force. Although being a sensitive issue for economies relatively closed to immigration (economies in East Asia, for example), their accelerated aging demographic may prompt transition toward easier migration policies. A World Bank (2016) study says there is evidence that aging populations in East Asia increasingly realize the need to raise historically low immigration rates.

Many economies in Asia could expand their role as source or host for migrant workers. Countries such as Cambodia, Indonesia, the Lao People's Democratic Republic, Mongolia, Myanmar, Papua New Guinea, India, the Philippines, Thailand, Timor-Leste, and Viet Nam have relatively young populations with domestic labor demand inadequate for the growing labor supply. Thus, these economies could deploy labor abroad. In contrast, developed but aging economies like Hong Kong, China; the Republic of Korea; Japan; and Singapore are unable to meet labor demand with their dwindling workforce. Hence, these economies would benefit from immigrant labor.

In estimating the required migration demands from source to host economies within the region, we compare two scenarios using 2010 as base year:

(i) deficit or surplus based on the projected population and dependency ratio (Case 1), and

(ii) deficit or surplus based on the projected population, using a constant 2010 total dependency ratio (0-14 and 65+ years) (Case 2)

For the analysis, the baseline scenario is when the economic life cycle across host and source economies are at their 2010 "stable state." It uses the standard workforce population and standard value of labor productivity - which also corresponds to the estimated total dependency ratio (the ratio of the dependent population aged 0-14 and 65+ out of the total workforce)-as calculated in the United Nations, Department of Economic and Social Affairs, Population Division database.

To reach the "stable state" of the economic life cycle in 2010, we account for the change in population (surplus or deficit) starting 2015 up to 2050 by using the estimates for Case 1. Using this method, we can compare expected workforce deficits of host countries from 2015 to 2050 and with the expected labor surplus from source economies under the two scenarios. The objective is to examine whether migration from labor surplus (or source) economies can cover the needs of labor deficit (or host) economies. Case 2 is interesting because we estimate the workforce deficits of host countries by holding the total dependency ratio constant and compare them with the projected labor surplus from source economies from 2015 to 2050.

Finally, we compute the difference between Case 1 and Case 2 results and compare them with changes in population.

\section{Change in Population Using Base Year 2010 (baseline scenario)}

We use the simple difference for computing the population deficit or surplus based on age group by the UN's forecast of age group population, using 2010 as baseline.

Table 7 shows potential host economies (including the PRC; Hong Kong, China; Japan; and the Republic of Korea) and potential source economies (including India and the Philippines, among others). All four host economies post higher and increasing surpluses for the population aged 65+ 
compared with the rest of the age demographic. The PRC holds the highest $65+$ aged surplus -260 million by 2050-and posts surpluses for the population aged 45-64, peaking at more than 100 million in 2035. Hong Kong, China posts surpluses of almost 200,000 in 2015 and up to 2 million by 2050 for the 65+ population. Japan is expected to have surplus of between 4 million and 10 million aged 65+ from 2015 up to 2050. And the Republic of Korea shows increasing surpluses for its population aged $65+$, reaching 12.3 million by 2050 .

These host economies also post large deficits, particularly in the 15-29 and 30-44 age groups. In fact, the entire Asia and Pacific region posts deficits in the working population group aged 15-29 starting in 2020. The PRC takes the lead with a deficit of 22 million in 2015, reaching 146 million by 2050. For the working population aged 30-44, the PRC also has a large 27 million deficit in 2015, reaching 106 million by 2050. Japan shows a deficit of over 1 million in the 15-29 working-age bracket in 2015 and is expected to reach almost 6 million by 2050. Meanwhile, the Republic of Korea is expected to have a 15-29 working-age deficit of more than 3 million by 2050 and 5 million in the 3044 working-age bracket.

In contrast, potential source economies show surpluses in workforce population (15-64) from 2015 to 2050. India posts large surpluses in its workforce population-32 million by 2025 for the 1529 age demographic, more than 113 million by 2040 for those aged 30-44 and more than 233 million for those 45-64 years old. However, India's fertility rate is gradually dropping; showing a growing deficit in population aged 0-14 of almost 54 million by 2050. In addition, the 65+ demographic surplus also increases from 2010 to 2050.

The Philippines continues to show a surplus in its young 0-14 year old population, reaching 4.1 million by 2040 . The country's workforce population remains robust, with increasing surpluses from 2010 to 2050 for the population aged 15-64. By 2050, the workforce aged 45-64 will have a 19 million surplus.

\section{Change in Population Holding Constant 2010 Total Dependency Ratio}

We now look at the change in population in host economies across various age ranges if dependency ratio is held constant at base year 2010. By holding the ratio constant, we can compute new population estimates from 2015 up to 2050 across all age brackets. The simple algebraic equation below shows how this is done:

$$
\begin{aligned}
& \text { Total dependency ratio }\left(R_{1}\right)=\frac{P_{0-14}+P_{65+}}{P_{15-64}} \times 100 \\
& \text { Total dependency ratio }\left(R_{2}\right)=\frac{P_{0-14}+P_{65+}}{P_{15-29}} \times 100 \\
& \text { Total dependency ratio }\left(R_{3}\right)=\frac{P_{0-14}+P_{65+}}{P_{30-44}} \times 100 \\
& \text { Total dependency ratio }\left(R_{4}\right)=\frac{P_{0-14}+P_{65+}}{P_{45-64}} \times 100
\end{aligned}
$$


Table 7: Change in Population of Economies at Standard Dependency Ratio (Case 1) (thousands)

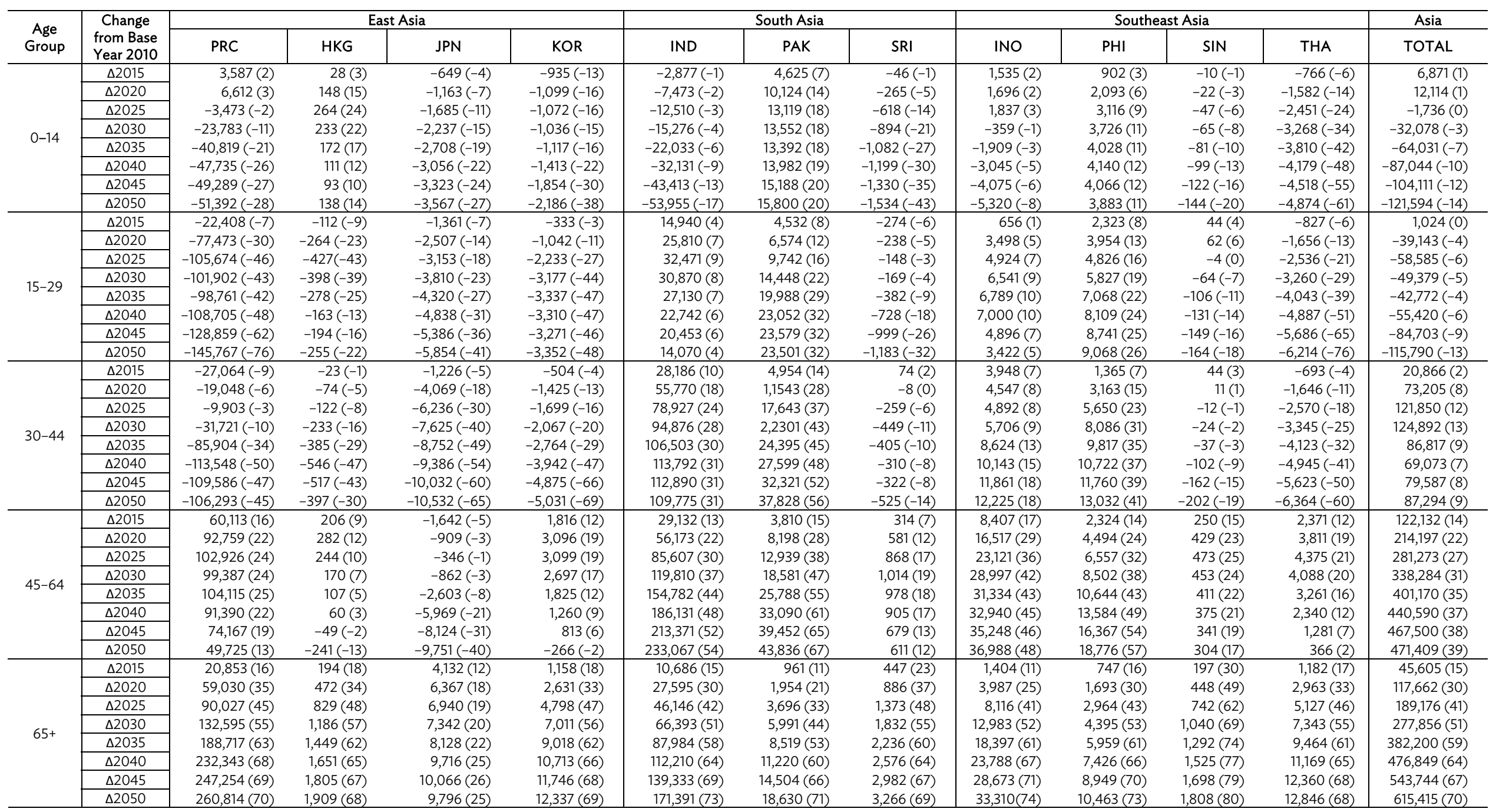

HKG = Hong Kong, China; IND = India; INO = Indonesia; JPN = Japan; KOR = Republic of Korea; PAK = Pakistan; PHI = Philippines; PRC = People's Republic of China; SIN = Singapore; SRI = Sri Lanka; THA = Thailand.

Note: Numbers in parentheses refer to the percent of total population of the age group.

Source: Authors' calculations based on data from the United Nations, Department of Economic and Social Affairs, Population Division. Special Aggregates. https://esa.un.org/unpd/wpp/Download/SpecialAggregates/Ecological/ 
Holding the total dependency ratio constant at time $t$ (where $t=2010$ ), we now compute new estimates for the population from 2015 to 2050:

$$
\begin{aligned}
& P_{15-29}=\frac{P_{0-14}+P_{65+}}{R_{2}} \times 100 \\
& P_{30-44}=\frac{P_{0-14}+P_{65+}}{R_{3}} \times 100 \\
& P_{45-64}=\frac{P_{0-14}+P_{65+}}{R_{4}} \times 100
\end{aligned}
$$

We then use the simple difference in computing the deficit or surplus of the new estimates of the population using Case 1 values as the baseline. We compare these gaps between host and source countries (Table 8). These gaps represent the maximum deficits for the host economies and maximum surpluses for source countries for each age range.

By economy, we find that to maintain the baseline scenario (UN population projections) until 2050, the PRC will need more than 350 million for its working population aged 15-29 years by 2050; 313 million for the population aged 30-44 years; and finally up to 145 million for the working population aged 45-64. Hong Kong, China will need to address a gap of 1.9 million for its working population aged 15-29; 2.4 million for the population aged 30-44; and finally, 2.7 million for the population aged 45-64. Japan will need to augment its labor force by 8.6 million for the 15-29 year old bracket; 14 million for its working population aged 30-44; and another 14 million for its working population aged 45-64. For the Republic of Korea, the country needs to augment its population to address a gap of more than 11 million in its working population aged 15-29; 14 million in its working population aged 30-44; and 10 million in its working population aged 45-64. These gaps represent the maximum deficit for each country across age ranges from 2015 to 2050.

As for source countries, in both India and Philippines the working populations aged 30-44 and 45-64 show surpluses from 2015 to 2050. We expect these estimates as the two countries have relatively young populations. For India, estimates for 2015, 2020, and 2025 show surplus of 8.9 million, 10.4 million, and 6.7 million, respectively for working populations aged 15-29 even after maintaining the 2010 dependency ratio. Similarly, the Philippines shows a surplus of 1.1 million, 1.2 million, and 0.4 million for years 2015, 2020, and 2025, respectively. In contrast, a deficit of 0.08 million, 0.2 million, 0.3 million, 0.7 million, and 1.4 million for years 2030, 2035, 2040, 2045, and 2050, respectively means that the Philippines still must rely on imported labor from 2030 to 2050 for the working population aged 15-29 to maintain its 2010 dependency ratio.

Table 8 shows the deficit to surplus ratio across working-age populations for Case 2. The 1529 working-age population group shows a regionwide deficit ranging from 4\% in 2015 and 63\% in 2050. In addition, the 30-44 age group also falls short of the regional deficit, requiring migration of around $32 \%$ of the age group population from outside the region in 2050 . This implies a more severe challenge for Asian policy makers if they are to effectively deal with fast growing dependency ratios. 
Table 8: Change in Population of Economies at Constant Dependency Ratio (Case 2) (thousands)

\begin{tabular}{|c|c|c|c|c|c|c|c|c|c|c|c|c|c|}
\hline \multirow{2}{*}{$\begin{array}{l}\text { Age } \\
\text { Group }\end{array}$} & \multirow{2}{*}{$\begin{array}{c}\text { Change } \\
\text { from Case } 1\end{array}$} & \multicolumn{4}{|c|}{ East Asia } & \multicolumn{3}{|c|}{ South Asia } & \multicolumn{4}{|c|}{ Southeast Asia } & \multirow{2}{*}{$\frac{\text { Asia }}{\text { TOTAL }}$} \\
\hline & & PRC & HKG & JPN & KOR & IND & PAK & SRI & INO & $\mathrm{PHI}$ & SIN & THA & \\
\hline \multirow{8}{*}{$15-29$} & $\Delta 2015$ & $-46,312(-20)$ & $-291(-33)$ & $-2,892(-18)$ & $-506(-7)$ & $8,960(2)$ & $496(1)$ & $-567(-11)$ & $-1,619(-2)$ & $1,123(3)$ & $-104(-12)$ & $-1,147(-10)$ & $-43,138(-4)$ \\
\hline & $\Delta 2020$ & $-141,675(-59)$ & $-765(-77)$ & $-4,794(-30)$ & $-2,228(-32)$ & $10,401(3)$ & $-2,152(-3)$ & $-692(-14)$ & $-902(-1)$ & 1,198 (4) & $-274(-32)$ & $-2,720(-24)$ & $-151,192(-15)$ \\
\hline & $\Delta 2025$ & $-190,331(-83)$ & $-1,309(-118)$ & $-5,462(-36)$ & $-5,118(-74)$ & $6,714(2)$ & $-2,407(-3)$ & $-701(-16)$ & $-2,782(-4)$ & $401(1)$ & $-552(-66)$ & $-4,597(-44)$ & $-219,727(-23)$ \\
\hline & $\Delta 2030$ & $-208,329(-99)$ & $-1,543(-143)$ & $-6,054(-41)$ & $-7,803(-112)$ & $-8,272(-2)$ & $327(0)$ & $-856(-20)$ & $-3,233(-5)$ & $-83(0)$ & $-832(-102)$ & $-6,399(-67)$ & $-260,129(-28)$ \\
\hline & $\Delta 2035$ & $-243,417(-126)$ & $-1,586(-156)$ & $-6,702(-47)$ & $-9,455(-138)$ & $-23,372(-7)$ & $4,156(6)$ & $-1,227(-30)$ & $-5,976(-9)$ & $-201(-1)$ & $-1,061(-133)$ & $-8,399(-93)$ & $-317,307(-35)$ \\
\hline & $\Delta 2040$ & $-289,266(-156)$ & $-1,586(-166)$ & $-7,765(-56)$ & $-10,510(-160)$ & $-38,578(-11)$ & $4,843(6)$ & $-1,736(-44)$ & $-9,061(-14)$ & $-308(-1)$ & $-1,255(-160)$ & $-10,273(-119)$ & $-392,555(-44)$ \\
\hline & $\Delta 2045$ & $-322,485(-175)$ & $-1,725(-184)$ & $-8,350(-61)$ & $-10,931(-179)$ & $-52,997(-16)$ & $2,126(3)$ & $-2,208(-58)$ & $-14,149(-22)$ & $-730(-2)$ & $-1,391(-183)$ & $-11,728(-142)$ & $-463,300(-53)$ \\
\hline & $\Delta 2050$ & $-350,598(-192)$ & $-1,907(-194)$ & $-8,592(-64)$ & $-11,212(-194)$ & $-75,857(-23)$ & $-1,376(-2)$ & $-2,450(-68)$ & $-1,8249(-28)$ & $-1,373(-4)$ & $-1,475(-200)$ & $-12,356(-156)$ & $-539,241(-63)$ \\
\hline \multirow{8}{*}{$30-44$} & $\Delta 2015$ & $-51,266(-16)$ & $-241(-19)$ & $-3,244(-17)$ & $-709(-7)$ & $23,811(7)$ & $2,530(5)$ & $-190(-4)$ & $1,939(3)$ & $501(2)$ & $-131(-12)$ & $-1,069(-8)$ & $-19,204(-2)$ \\
\hline & $\Delta 2020$ & $-84,050(-32)$ & $-679(-59)$ & $-7,083(-40)$ & $-2,829(-30)$ & $44,496(12)$ & $6,300(11)$ & $-417(-9)$ & $664(1)$ & 1,177 (4) & $-387(-35)$ & $-2,892(-23)$ & $-28,992(-3)$ \\
\hline & $\Delta 2025$ & $-95,613(-41)$ & $-1,190(-121)$ & $-9,280(-54)$ & $-5,114(-63)$ & $60,082(16)$ & $10,343(17)$ & $-757(-16)$ & $-1,910(-3)$ & $2,461(8)$ & $-661(-63)$ & $-4,984(-42)$ & $-23,610(-2)$ \\
\hline & $\Delta 2030$ & $-139,472(-59)$ & $-1,619(-160)$ & $-10,581(-64)$ & $-7,544(-105)$ & $66,237(18)$ & $13,817(21)$ & $-1,067(-23)$ & $-2,921(-4)$ & $3,827(12)$ & $-933(-94)$ & $-7,021(-63)$ & $-64,605(-7)$ \\
\hline & $\Delta 2035$ & $-232,360(-98)$ & $-1,968(-174)$ & $-11,891(-75)$ & $-10,007(-142)$ & $69,552(19)$ & $14,884(21)$ & $-1,166(-26)$ & $-2,643(-4)$ & $4,580(14)$ & $-1,168(-123)$ & $-9,224(-89)$ & $-161,891(-17)$ \\
\hline & $\Delta 2040$ & $-296,356(-130)$ & $-2,268(-182)$ & $-13,243(-86)$ & $-12,467(-176)$ & $68,926(19)$ & $16,659(23)$ & $-1,217(-30)$ & $-4,032(-6)$ & $4,657(14)$ & $-1,434(-155)$ & $-11,252(-118)$ & $-237,203(-25)$ \\
\hline & $\Delta 2045$ & $-305,622(-147)$ & $-2,371(-195)$ & $-13,938(-94)$ & $-13,944(-196)$ & $59,149(16)$ & $19,432(26)$ & $-1,411(-37)$ & $-4,949(-7)$ & 4,935 (14) & $-1,633(-180)$ & $-12,699(-145)$ & $-261,410(-28)$ \\
\hline & $\Delta 2050$ & $-313,673(-164)$ & $-2,397(-208)$ & $-14,140(-98)$ & $-14,337(-204)$ & $43,980(12)$ & $22,882(31)$ & $-1,666(-46)$ & $-6,902(-10)$ & $5,509(16)$ & $-1,756(-197)$ & $-13,557(-165)$ & $-289,573(-32)$ \\
\hline \multirow{8}{*}{$45-64$} & $\Delta 2015$ & $37,417(12)$ & $-66(-4)$ & $-4,224(-17)$ & $1,600(14)$ & $25,608(9)$ & $2,100(6)$ & $48(1)$ & $6,939(12)$ & $1,672(8)$ & $50(4)$ & $2,002(12)$ & $85,558(10)$ \\
\hline & $\Delta 2020$ & $31,801(10)$ & $-475(-29)$ & $-4,767(-21)$ & $1,613(15)$ & $47,095(15)$ & 4,500 (11) & $170(4)$ & $13,680(23)$ & 2,995 (14) & $-29(-2)$ & 2,587 (17) & $121,004(13)$ \\
\hline & $\Delta 2025$ & $22,548(7)$ & $-1,090(-69)$ & $-4,241(-21)$ & $-508(-5)$ & $70,432(22)$ & $7,790(16)$ & $368(9)$ & $18,152(30)$ & $4,150(17)$ & $-273(-22)$ & $2,002(14)$ & $149,706(15)$ \\
\hline & $\Delta 2030$ & $-1,661(-1)$ & $-1,561(-106)$ & $-4,646(-24)$ & $-3,088(-30)$ & $96,747(28)$ & $12,597(24)$ & $393(10)$ & $22,694(37)$ & $5,287(20)$ & $-593(-48)$ & 475 (4) & $167,643(17)$ \\
\hline & $\Delta 2035$ & $-33,230(-13)$ & $-1,870(-142)$ & $-6,621(-37)$ & $-5,825(-61)$ & $125,027(35)$ & $19,079(35)$ & $214(5)$ & $23,102(36)$ & $6,691(24)$ & $-890(-73)$ & $-1,753(-14)$ & 177,191 (19) \\
\hline & $\Delta 2040$ & $-80,045(-35)$ & $-2,091(-180)$ & $-10,906(-63)$ & $-7,743(-93)$ & $150,002(41)$ & $25,373(44)$ & $-7(0)$ & $22,583(34)$ & $9,006(31)$ & $-1,156(-101)$ & $-3,859(-32)$ & $164,837(18)$ \\
\hline & $\Delta 2045$ & $-109,673(-47)$ & $-2,364(-199)$ & $-13,123(-79)$ & $-8,764(-118)$ & $170,094(47)$ & $30,360(49)$ & $-415(-10)$ & 22,967 (34) & $1,1214(37)$ & $-1,350(-124)$ & $-5,674(-50)$ & 162,189 (17) \\
\hline & $\Delta 2050$ & $-144,754(-62)$ & $-2,740(-209)$ & $-14,368(-89)$ & $-10,094(-139)$ & $180,083(50)$ & $33,293(49)$ & $-536(-14)$ & $23,013(34)$ & $13,097(42)$ & $-1,482(-142)$ & $-6,703(-64)$ & $136,181(14)$ \\
\hline
\end{tabular}

HKG = Hong Kong, China; IND = India; INO = Indonesia; JPN = Japan; KOR = Republic of Korea; PAK = Pakistan; PHI = Philippines; PRC = People's Republic of China; SIN = Singapore; SRI = Sri Lanka; THA = Thailand.

Note: Numbers in parentheses refer to the percent of total population of the age group.

Source: Authors' calculations based on data from the United Nations, Department of Economic and Social Affairs, Population Division. Special Aggregates. https://esa.un.org/unpd/wpp/Download/SpecialAggregates/Ecological/ 


\section{Augmenting Labor Force by Increasing the Fertility Rate}

A major driver of aging in the region-especially in East Asia-has been a sharp decline in fertility, significantly faster than the global decline. As a result, fertility rates in these economies are now among the lowest in the world. In richer East Asian economies (the PRC; Hong Kong, China; Japan; the Republic of Korea), total fertility rates declined dramatically from an average of 4.6 children per woman in 1950-1955 to 1.4 children per woman in 2010-2015-the PRC fell to 1.6 children per woman from 6.1; Hong Kong, China 1.2 children from 4.4; Japan 1.4 children from 3; and the Republic of Korea 1.3 children 5.1. In contrast, the average total fertility rate of Asia is 2.6 children per woman in 20102015 from an average 5.8 in 1950-1955.

According to a recent World Bank report, fertility rates are projected to continue to decline in countries with the youngest populations and to flatten across those in the middle (World Bank 2016). This can been seen using age-specific fertility rates, which measures the annual number of births to women of a specified age or age group per 1,000 women in that age group.

In this section, we analyze the impact of constant/increased fertility rates using the agespecific fertility rate (ASFR) - computed as the ratio of the number of live births to women in a particular age group over a period of time (numerator) to an estimate of the number of person-years lived by women in that same age group during the same period of time (denominator) - expressed as births per 1,000 women. We compare the results based on two scenarios using 2010-2015 as base year:

Case 1: Total population using standard ASFR and base year 2010-2015 (baseline scenario). The Case 1 scenario does not need further computation as the estimates already reflect the UN population projections across age groups. However, the charts are presented together with the Case 2 scenario in Figure A.4 in the Appendix.

Case 2: Total population using projected ASFR and base year 2010-2015 (baseline scenario). ${ }^{4}$ In calculating new estimates of the population across age groups in economies with declining fertility rates starting 2010-2015 up to 2045-2050, the projected ASFR is computed based on the growth required for the total fertility rate to reach the 2.1 replacement level. See the Appendix table for age-specific fertility rate adjustments (Table A.1).

We use several methods in computing for the new population estimates:

\section{(a) 1st generation}

(i) Compute for the number of person-years lived by women in age groups-1519, 20-24, 25-29, 30-34, 35-39, 40-44, 45-49:

$$
\begin{aligned}
& A S F R_{n}=\frac{B_{n}}{W_{n}} \times 1000 \\
& W_{n}=\frac{B_{n}}{A S F R_{n}} \times 1000
\end{aligned}
$$

4 The projected higher ASFR is computed using the growth required for the total fertility rate to reach the 2.1 replacement level. 
where, $\quad A S F R_{n}=$ age-specific fertility rate at each age band

$B_{n} \quad$ = number of births by 5 -year age group of mother (thousands)

$W_{n}$ = number of person-years lived by women

(ii) Compute for births projected using the ASFR for 2010-2015:

$$
B_{n^{\prime}}=\frac{\operatorname{ASFR}_{(n, 2010-2015)}}{1000} \mathrm{X} \quad W_{n}
$$

where, $\quad \operatorname{ASFR}_{(n, 2010-2015)}=$ age-specific fertility rate at each age band at 2010-2015

$B_{n \prime}=$ new estimate of births by 5 -year age group of mother (thousands) at constant ASFR

$W_{n} \quad$ = number of person-years lived by women

(iii) Compute for the birth surplus resulting to the new estimate of births $\left(B_{1}\right)$ :

$$
\text { Birth surplus }\left(B_{S}\right)=B_{1},-B_{1}
$$

(iv) Compute for the total surplus across age groups: 15-19, 20-24, 25-29, 30-34, 35-39, 40-44, 45-49:

$$
\text { Total surplus }=B_{1 s}+B_{2 s}+B_{3 s}+B_{4 s}+B_{5 s}+B_{6 s}+B_{7 s}
$$

where, $\quad B_{1 s}=$ birth surplus at 15-19 age group of mother (thousands)

$B_{2 s}=$ birth surplus at 20-24 age group of mother (thousands)

$B_{3 s}=$ birth surplus at 25-29 age group of mother (thousands)

$B_{4 s}=$ birth surplus at 30-34 age group of mother (thousands)

$B_{5 s}=$ birth surplus at 35-39 age group of mother (thousands)

$B_{6 s}=$ birth surplus at 40-44 age group of mother (thousands)

$B_{7 s}=$ birth surplus at 45-49 age group of mother (thousands)

Compute for the new total, accounting for the under -5 mortality rate:

$$
\begin{aligned}
& \text { Number of deaths }\left(D_{1}\right)=\frac{M R * \text { total surplus }}{1000} \\
& \text { New total }=B_{1 s}-\left(D_{1} / 1000\right)
\end{aligned}
$$

(v) Compute for the domino effect of children born at 2015-2020. In this step, we use an expanded method of accounting for the age evolution of children born in 2015-2020 (0-4) up to 2045-2050 (30-34). We also account for the crude death rate of children starting at the 5-9 age group until 30-34.

\section{(b) 2nd generation}

The second generation will account for women of childbearing age in the above expanded computation of surplus population. The youngest female population of childbearing age starts by 2030-2035. 
(i) Compute for the number of person-years lived by women in age groups15-19, 20-24, 25-29, 30-34:

$$
\frac{X_{1}}{Y_{1}}=\frac{X_{2}}{Y_{2}}
$$

where, $\quad X_{1}=$ number of childbearing women

$Y_{1}=$ number of person-years lived by women $\left(1^{\text {st }}\right.$ generation $)$

$X_{2}=$ number of child-bearing women

$Y_{2}=$ number of person-years lived by women $\left(2^{\text {nd }}\right.$ generation $)$

(ii) Repeat similar computation based on 1st generation method

Based on the country analysis in the Appendix table, adjusting the population by increasing the fertility rate starting 2010-2015 shows a significant addition to the population aged 0-14 and 15-29 in aging economies - the PRC; Hong Kong, China; Japan; and the Republic of Korea. In Hong Kong, China, the population aged 0-14 will reach 981,000 by 2050 under Case 1 and increases to 1.6 million in Case 2. Further, the population aged 15-29 is estimated at 1.1 million in 2050 under Case 1 and will reach 1.6 million in Case 2.

In Japan, the 1 scenario accounts for 13.3 million in 2050 for the population aged $0-14$. Projecting the fertility rate at a higher level will result in an increase of more than 21 million in 2050 for the same age group. Meanwhile, the population in 2050 for the 15-29 age group accounts for 14 million under Case 1 and almost 20 million in Case 2.

A more substantial increase is observed in the PRC, wherein the Case 1 scenario accounts for 182 million in 2050 for the population aged 0-14, but will reach 303 million under Case 2. The population aged 15-29 is estimated at 190 million in 2050 under Case 1 and will reach 256 million under Case 2. Finally, the population in 2050 for the 30-44 age group accounts for 234 million under Case 1 and 260 million under Case 2.

In the Republic of Korea, the population aged 0-14 reaches 5.8 million by 2050 under Case 1 and increases to more than 9 million under Case 2. Further, the population aged 15-29 is estimated at 7 million in 2050 under Case 1 and will reach 10.2 million under Case 2. Finally, the population aged 30-44 is estimated at 7.3 million in 2050 under Case 1 and will reach 8.6 million under Case 2.

Given the higher increase in young dependents than working-age population under a constant fertility rate, we expect the dependency ratios across economies to increase but taper as the additional young dependent population reaches working age starting 2030. In Hong Kong, China, the ratios diverge starting 2020 as the projected fertility rate causes a temporary increase in dependency ratio, but will converge by 2050. In Japan, the difference in ratio starts in 2020 and will converge by 2050. In the Republic of Korea, the variation starts in 2020 and will converge by 2045 (Figure 9). 
Figure 9: Dependency Ratios: Baseline (Case 1) versus Projected Fertility Rate (Case 2) (base year $=2010-2015)$
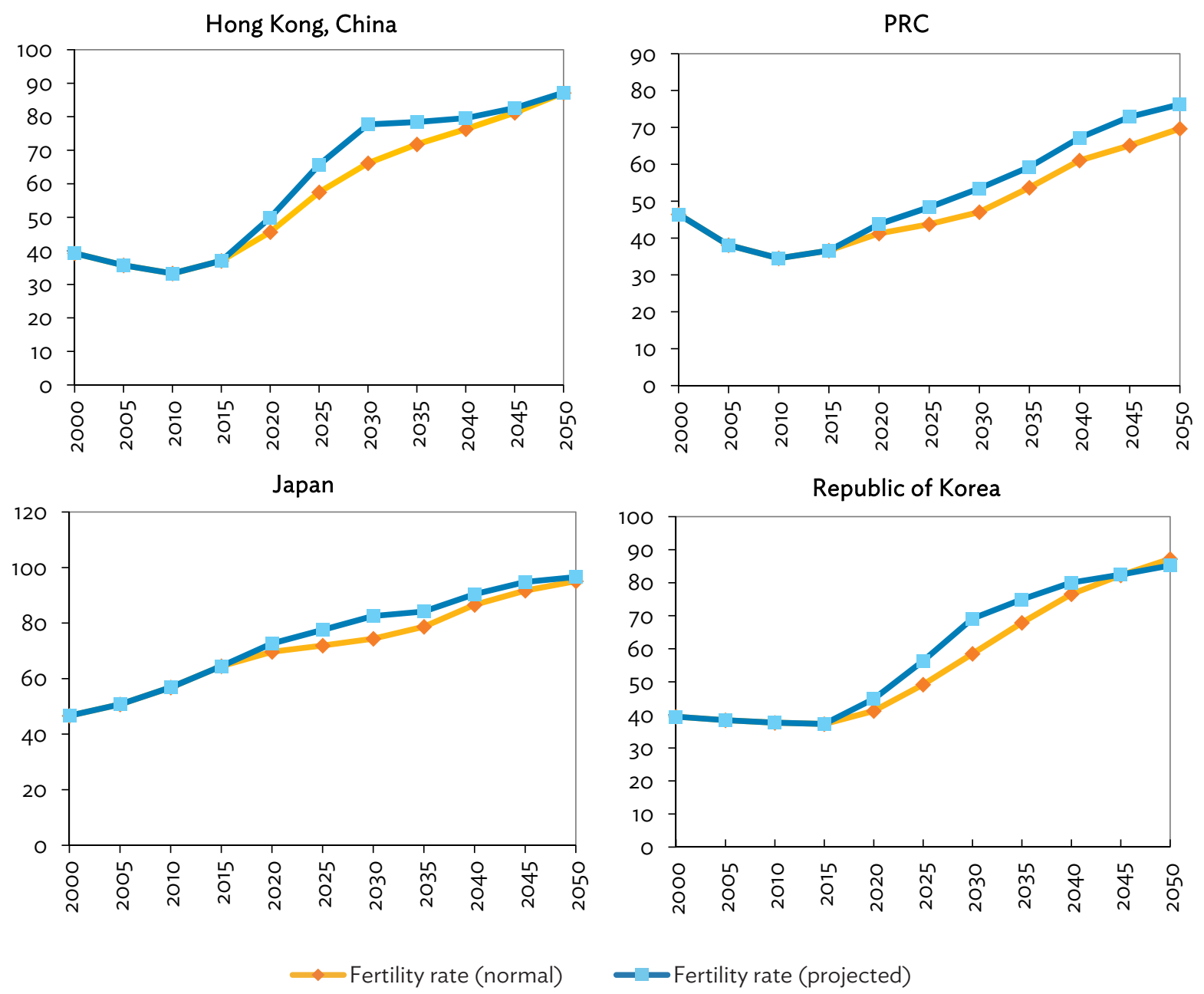

PRC $=$ People's Republic of China.

Source: Authors' calculations based on data from the United Nations, Department of Economic and Social Affairs, Population Division. Special Aggregates. https://esa.un.org/unpd/wpp/Download/SpecialAggregates/Ecological/

\section{CONCLUSION}

Much remains to be explored in the study of aging economies-most long-term trends and the ways to address them remain speculative. But the fact remains that Asia will become home to $56 \%$ of the elderly global population in 2015 and will increase to $62 \%$ by 2050 -a projected 1.3 billion people aged 60 years or over. The speed of aging in the region (especially East Asia) catalyzes the need for policy makers, communities, and citizens to help address this phenomenon. This paper discusses three possible channels of augmenting the workforce population, particularly for the aging economies in the region. 
Extending the retirement age is expected to reduce the dependency ratio by increasing the number of workers relative to the number of consumers. However, there are risks and benefits in implementing the policy. Countries could gradually raise the retirement age and implement reverse incentives for early retirement. But the health risk for older working people could also increase. The World Bank says policy makers could also incentivize workplace adjustments to accommodate older workers and protect their physical well-being (through, for example, flexible and part-time work arrangements).

Meanwhile, increasing migration flow will require proactive efforts in both host and source economies. The magnitude of these changes critically depends on policy decisions (especially in the areas of health care and pension provision) taken nationally, and business decisions taken locally. Singapore and Hong Kong, China offer examples of the economic benefits of more open immigration policies (World Bank 2016). Other countries are exploring ways to overcome traditionally limited reliance on immigration. Just recently, the Japanese government embarks on new policies to ease foreign worker entry, easing delivery of permanent-residency cards for skilled migrants. As shown in our simulation, the gaps filled by sending workers to host countries are substantial in addressing labor shortages.

Studies on increasing fertility rates suggest that increased expenditures on family policy programs aimed at empowering women through opportunities to combine family and employmentthereby reducing the opportunity cost of children-generate positive fertility responses. In Japan, plans include steps to raise the birth rate, such as easier access to childcare and tax incentives. Other proposals being considered are easing the tax burden for some part-time employees and making interest-free loans available for higher education (White 2015). While increasing fertility rates may entail additional short-term burdens on the economy, policy makers need to take urgent action to avoid being trapped in the vicious cycle of shrinking populations and rising dependency ratios. 


\section{APPENDIX}

Figure A.1: Workforce Population in Asia and the Pacific (millions)
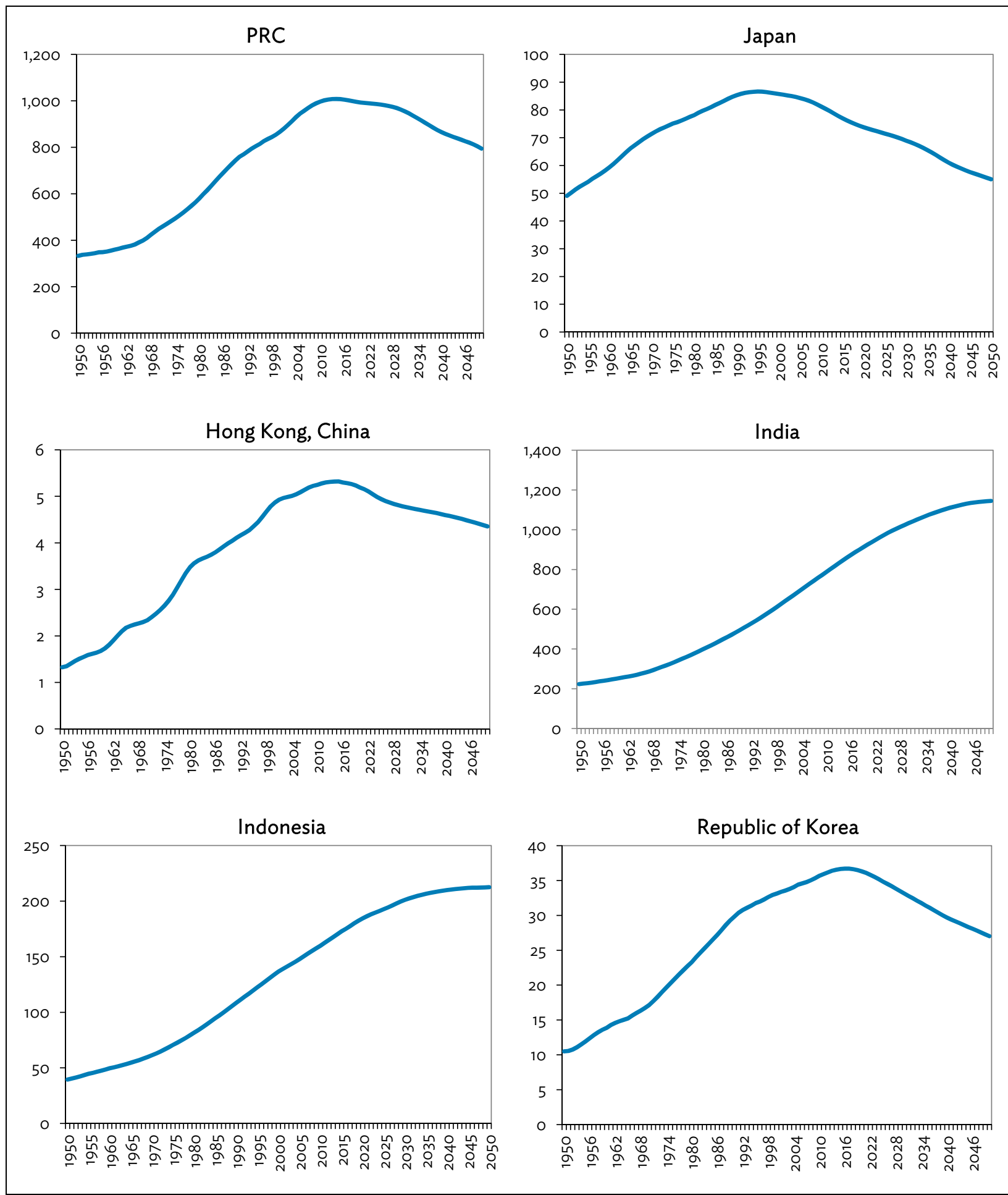
Figure A.1 continued

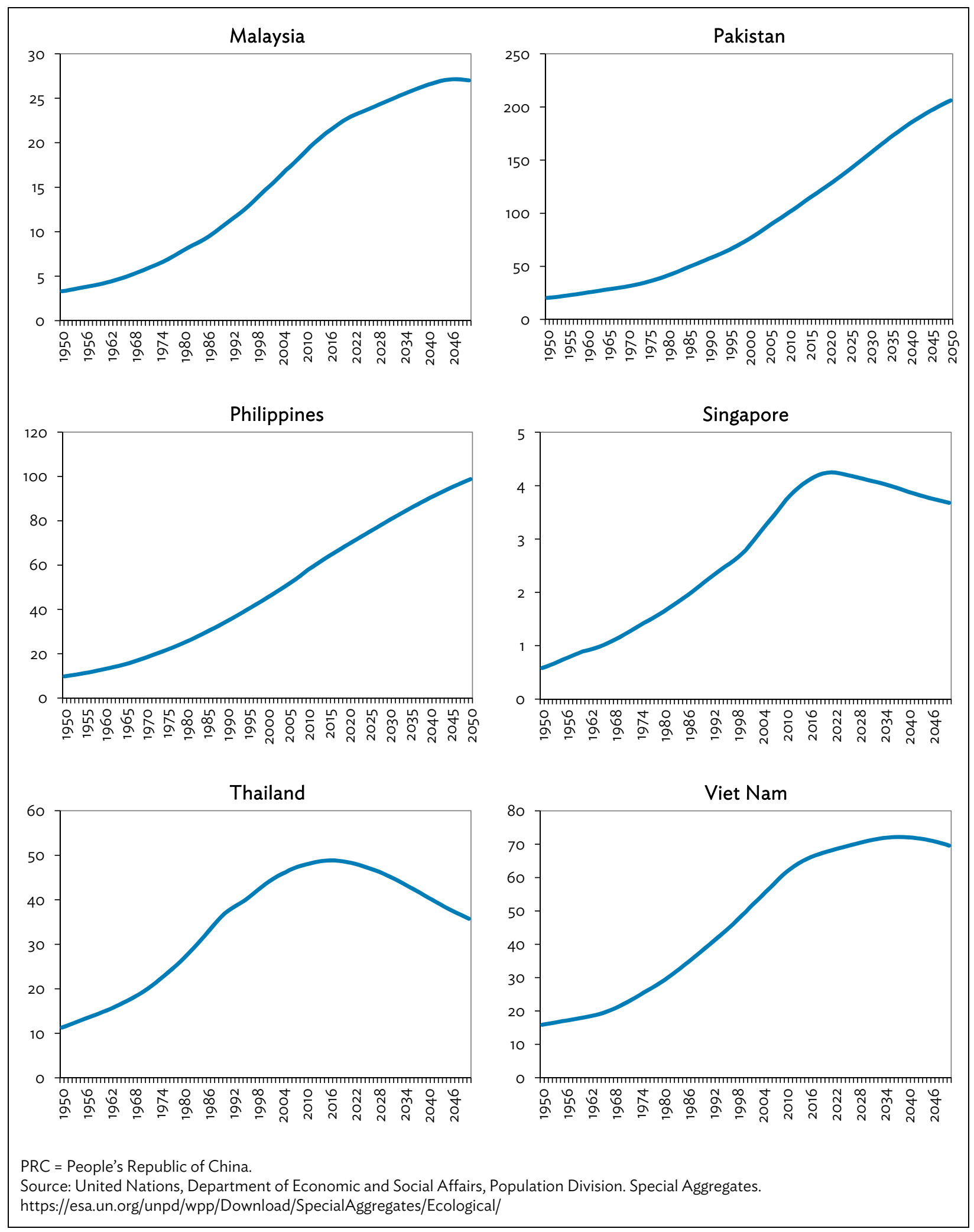


Figure A.2: Young, Old, and Total Dependency Ratios in Asia and the Pacific
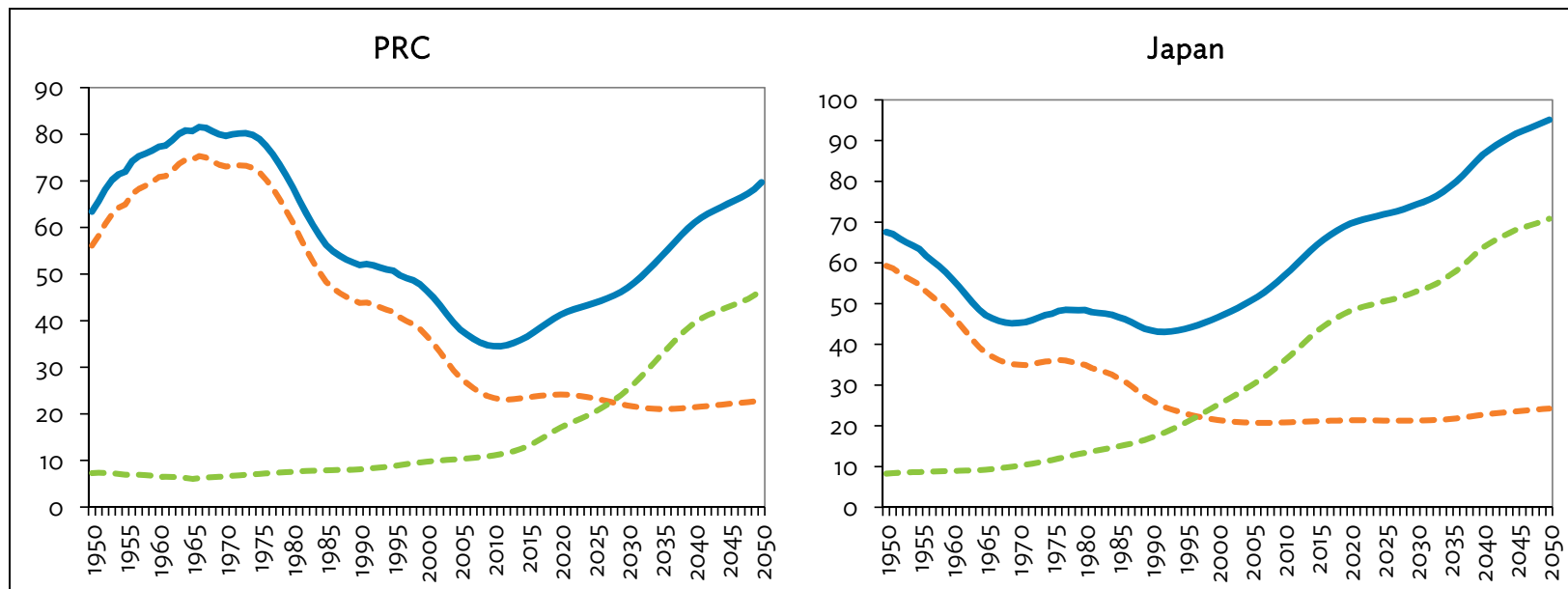

Hong Kong, China

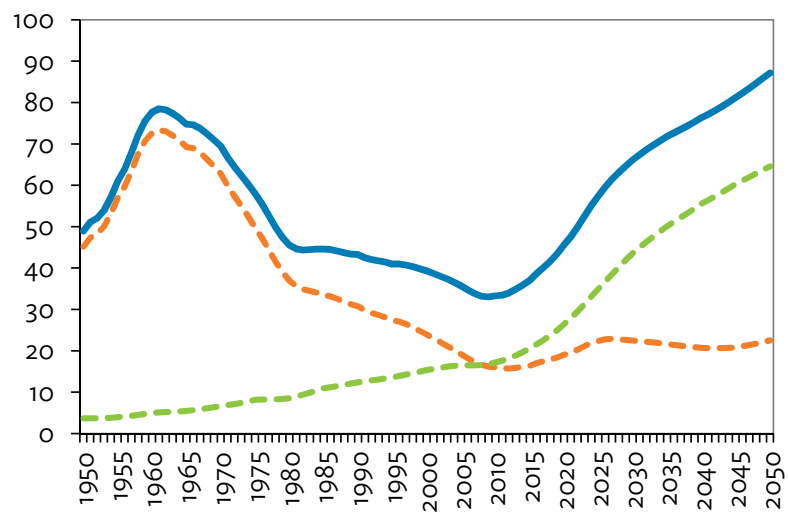

Indonesia

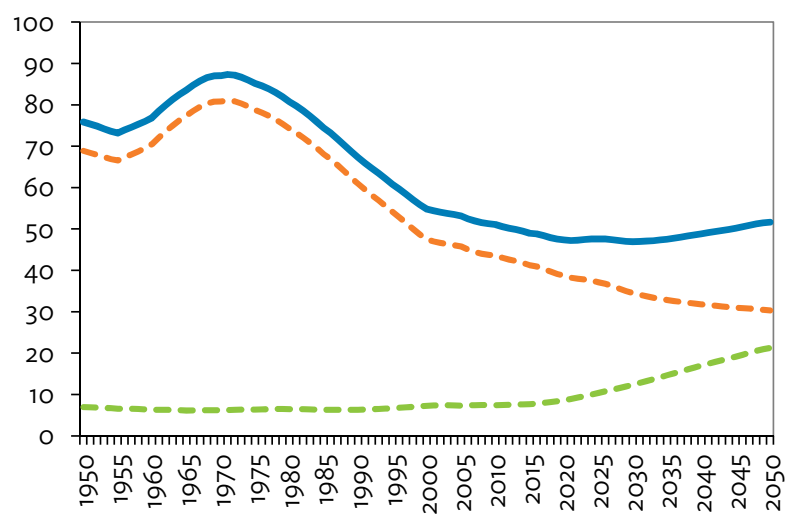

India

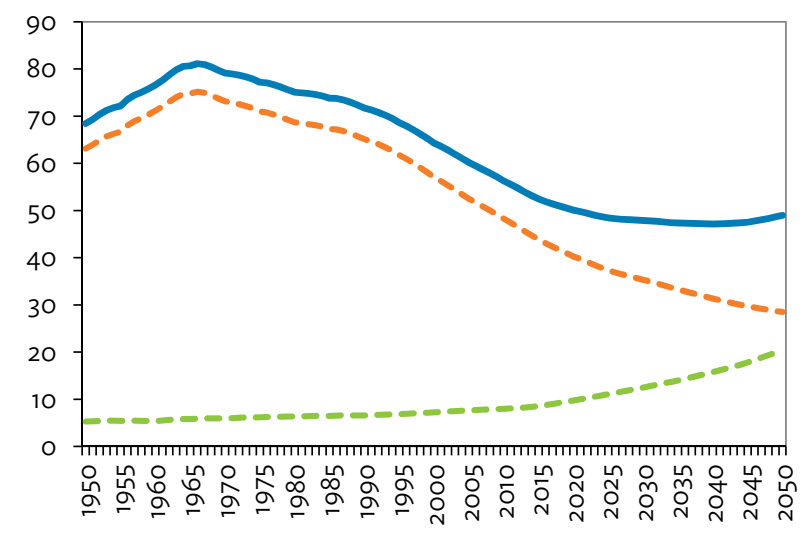

Republic of Korea

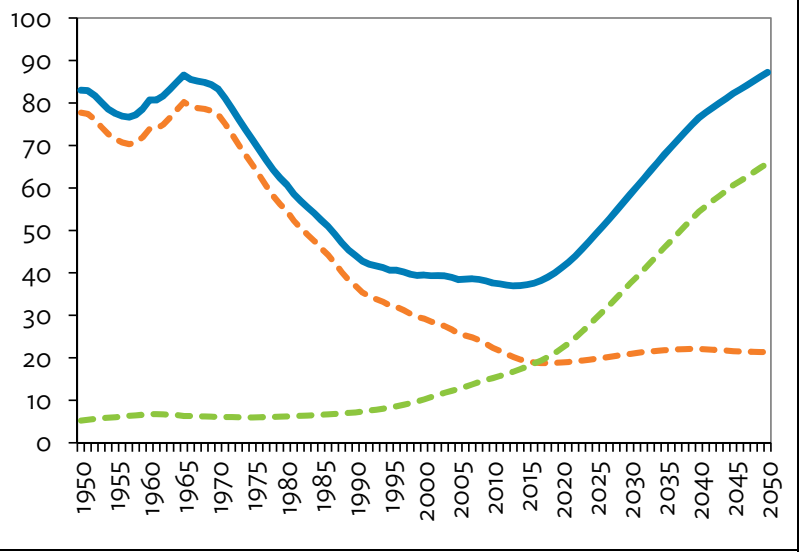


Figure A.2 continued
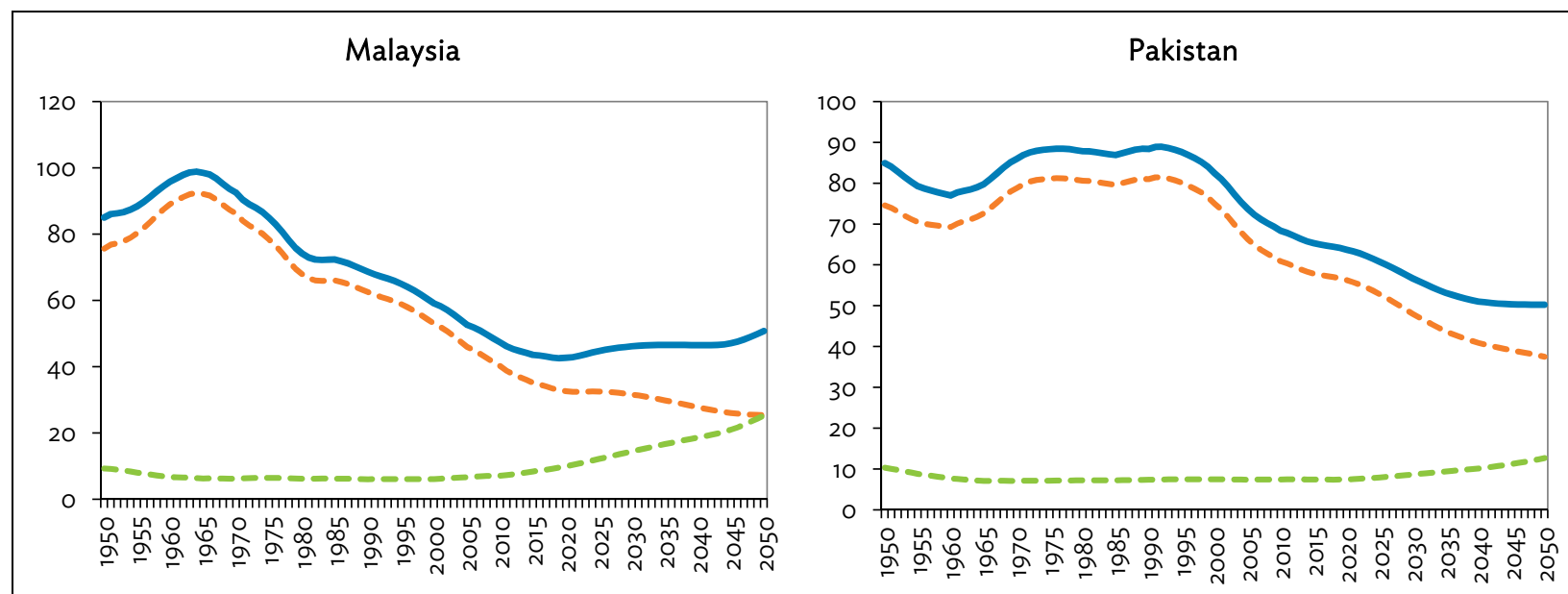

Philippines
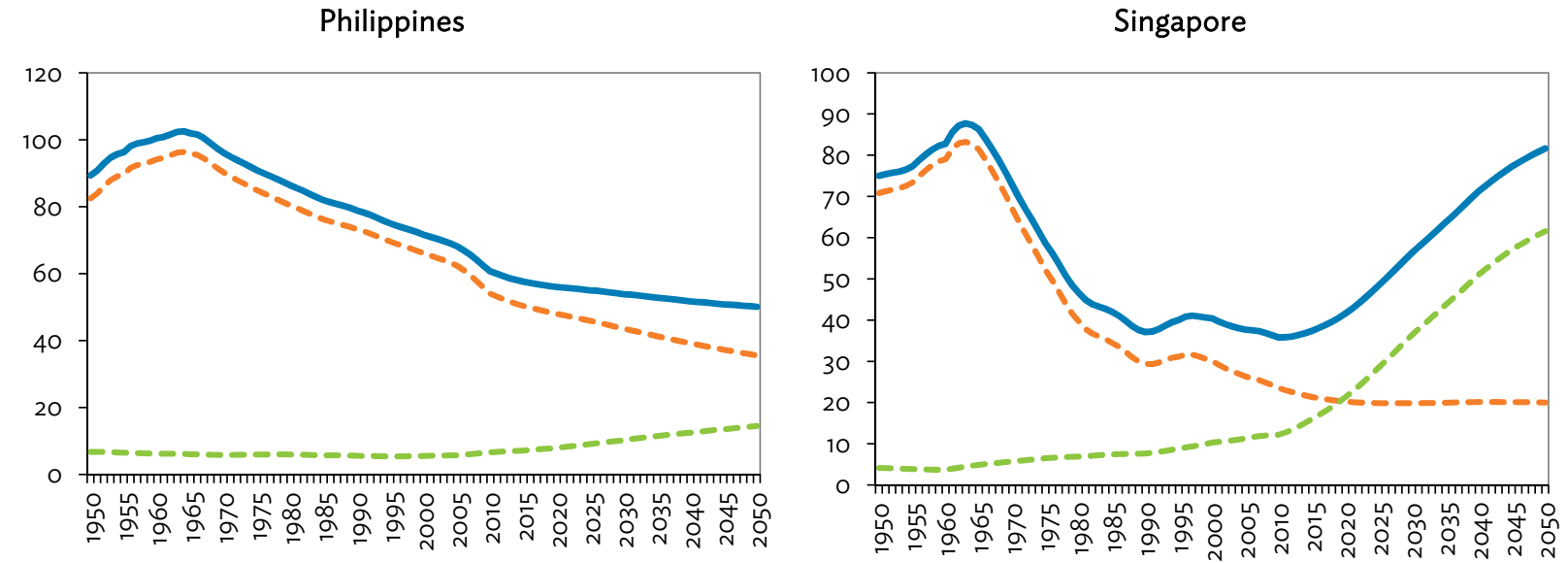

Thailand

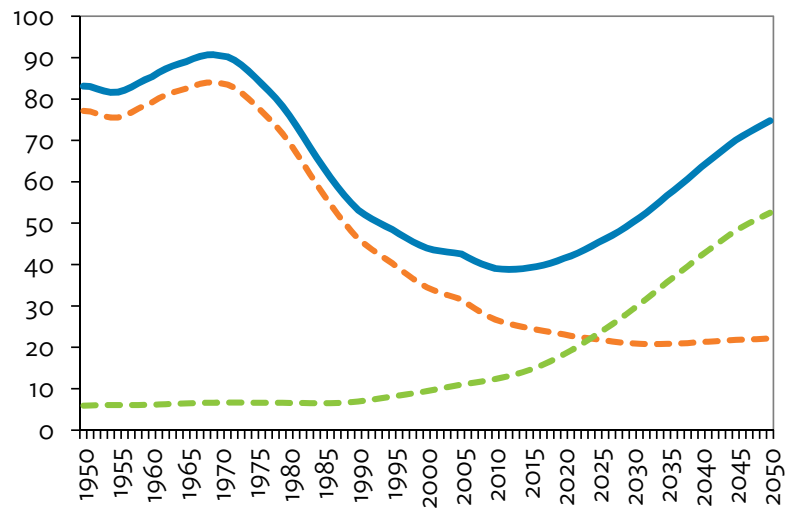

Viet Nam

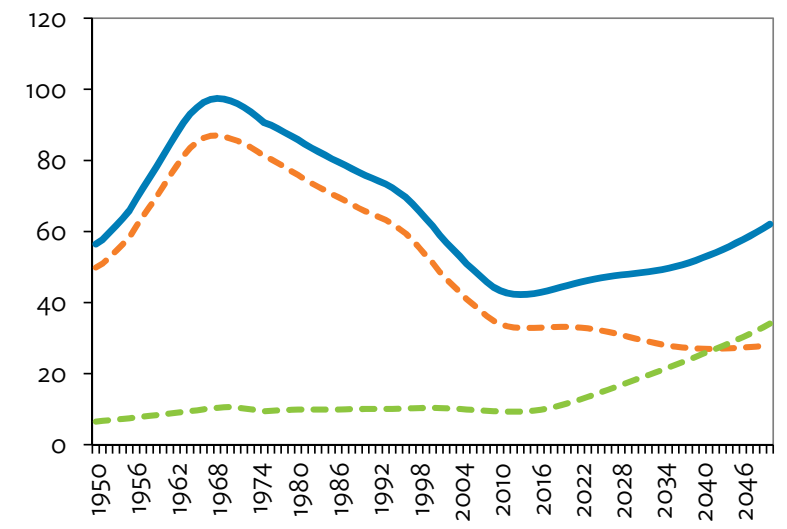

$$
\text { Total } \quad-\infty-\infty \text { Young } \quad-\infty \text { Old }
$$

PRC = People's Republic of China.

Source: Authors' calculations using data from the United Nations, Department of Economic and Social Affairs, Population Division. Special Aggregates. https://esa.un.org/unpd/wpp/Download/SpecialAggregates/Ecological/ 
Figure A.3: Economic Life Cycle: Consumption versus Labor Income (Aggregate Levels)
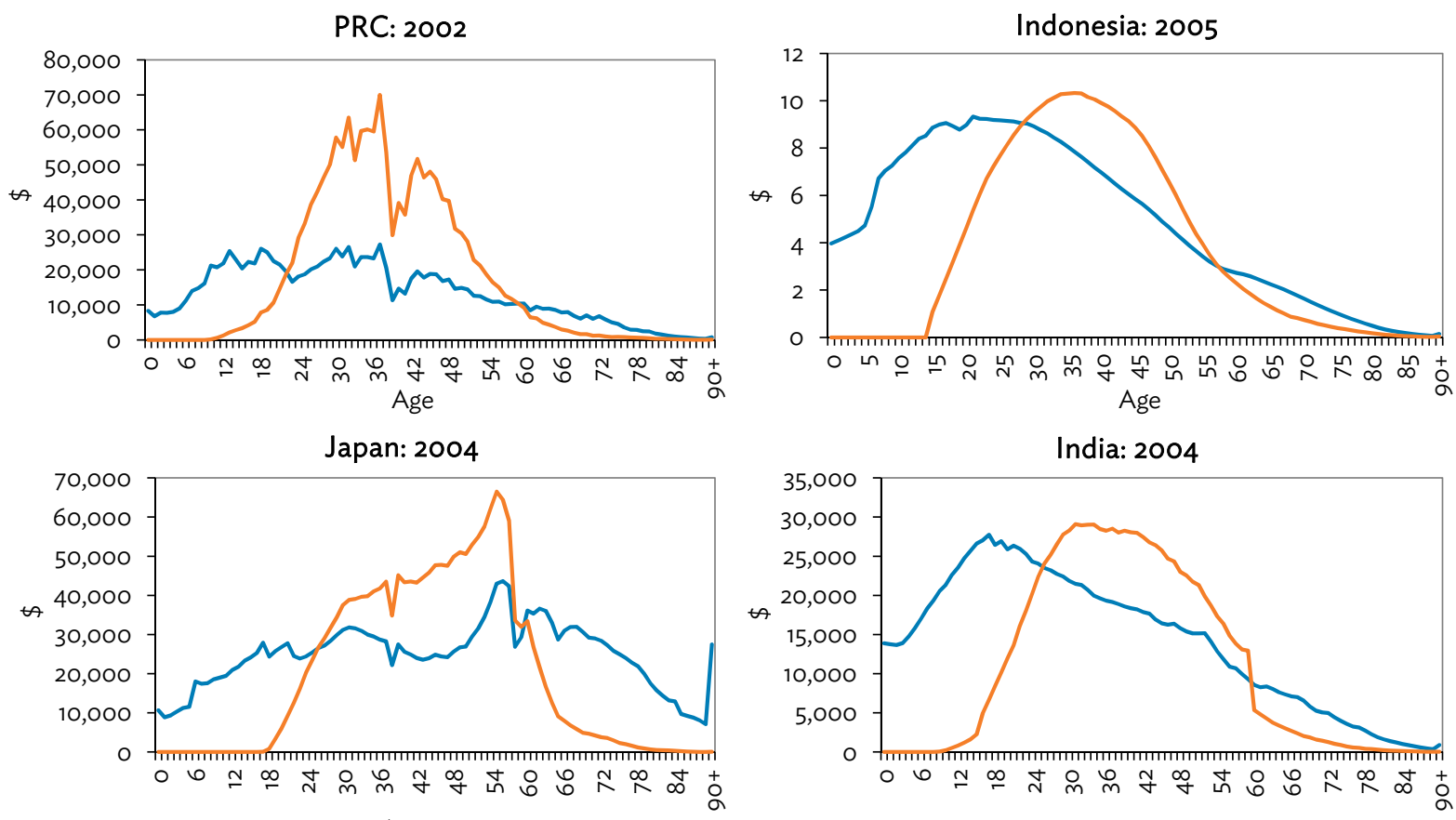

Age

$$
\text { Age }
$$

Republic of Korea: 2000
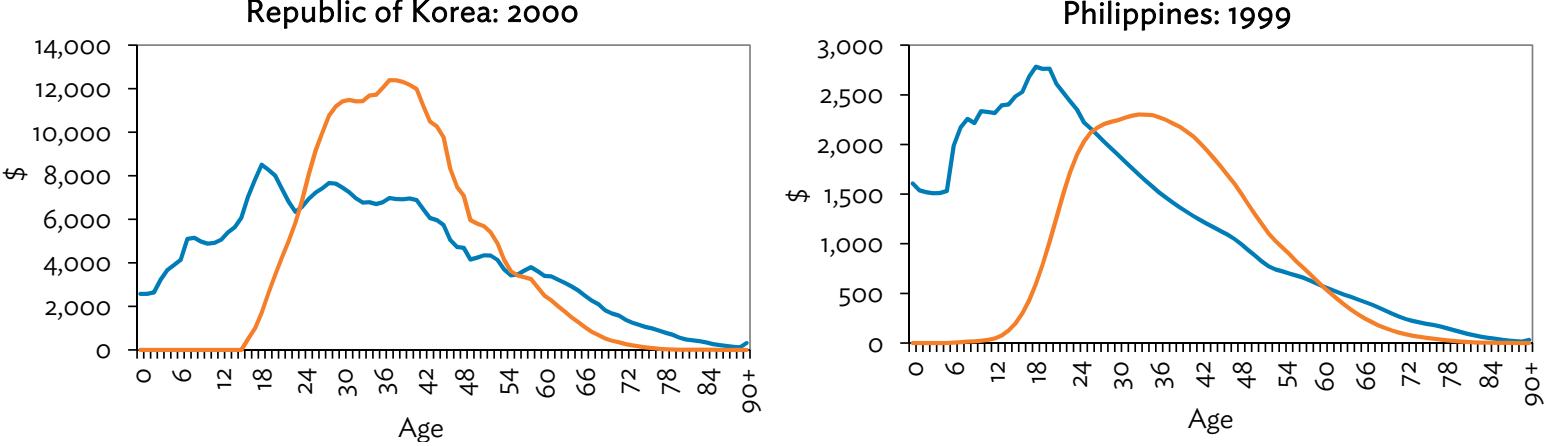

United States: 2003
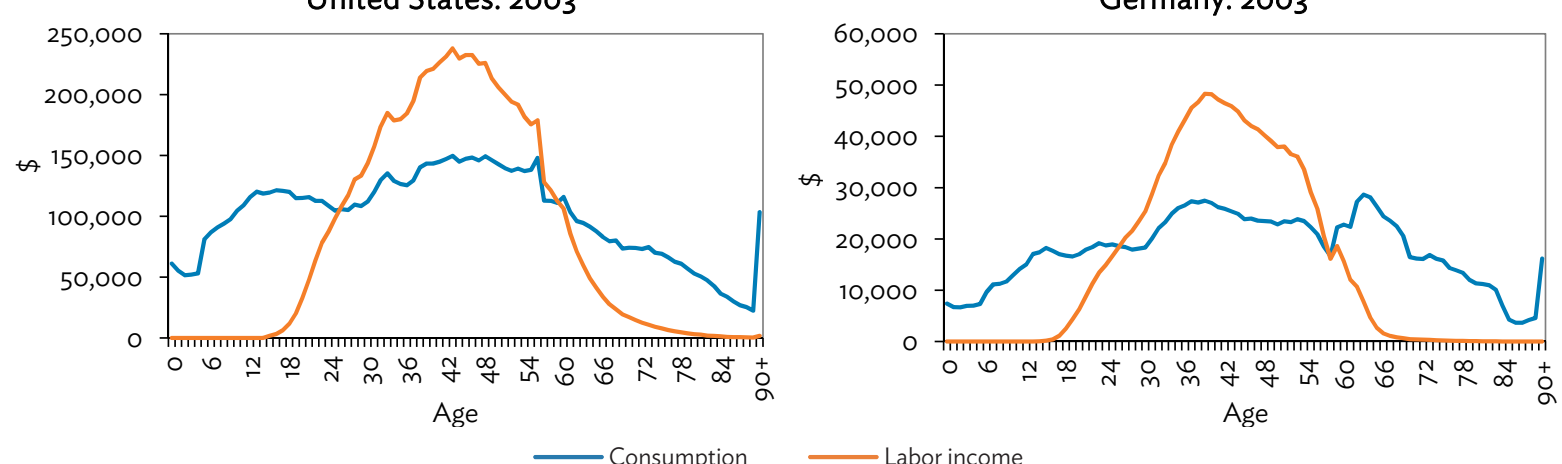

PRC $=$ People's Republic of China, US = United States.

Note: Based on Annual Aggregate Flows purchasing power parity (PPP) of selected countries. Converting local currency to US dollars based on PPP ratios.

Source: Data taken directly from the National Transfer Accounts website. http://www.ntaccounts.org/ 


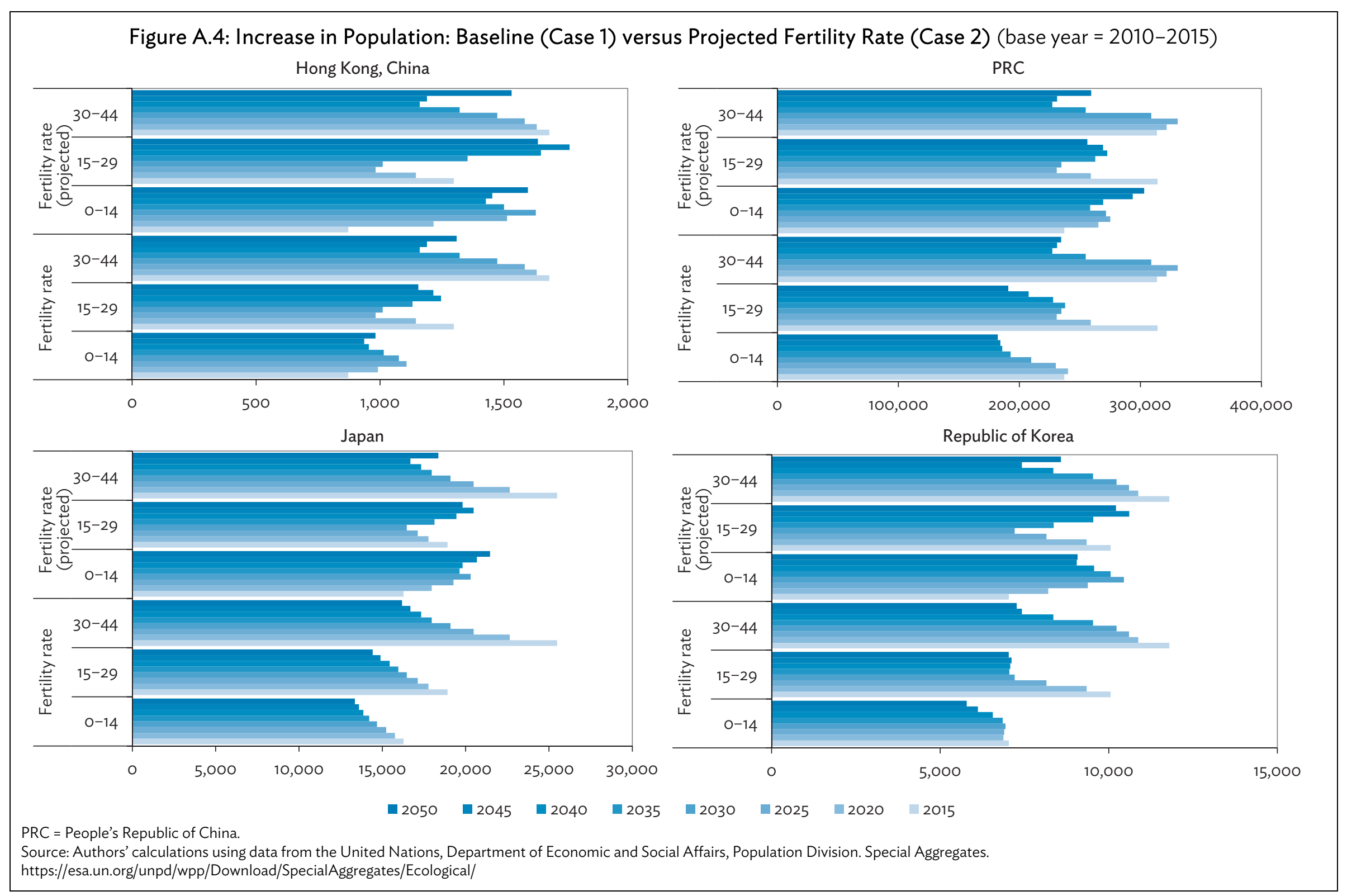


Table A.1: Increase in Fertility Rate: Baseline (Case 1) versus Projected Fertility Rate (Case 2)

(base year $=2010-2015$ )

\begin{tabular}{|c|c|c|c|c|c|c|c|c|c|c|c|c|c|c|c|c|}
\hline & \multicolumn{16}{|c|}{$15-19$} \\
\hline & \multicolumn{2}{|c|}{$2010-2015$} & \multicolumn{2}{|c|}{$2015-2020$} & \multicolumn{2}{|c|}{$2020-2025$} & \multicolumn{2}{|c|}{$2025-2030$} & \multicolumn{2}{|c|}{$2030-2035$} & \multicolumn{2}{|c|}{$2035-2040$} & \multicolumn{2}{|c|}{$2040-2045$} & \multicolumn{2}{|c|}{$2045-2050$} \\
\hline & Case 1 & Case 2 & Case 1 & Case 2 & Case 1 & Case 2 & Case 1 & Case 2 & Case 1 & Case 2 & Case 1 & Case 2 & Case 1 & Case 2 & Case 1 & Case 2 \\
\hline $\begin{array}{l}\text { East Asia } \\
\text { Hong Kong, China }\end{array}$ & 3.5 & 6.1 & 2.9 & 4.7 & 2.8 & 4.3 & 2.7 & 4.0 & 2.8 & 3.9 & 2.9 & 3.9 & 2.9 & 3.9 & 3.0 & 3.9 \\
\hline PRC & 7.5 & 10.2 & 7.1 & 9.4 & 7.0 & 9.1 & 6.9 & 8.7 & 6.9 & 8.7 & 7.0 & 8.7 & 7.1 & 8.7 & 7.2 & 8.7 \\
\hline Japan & 4.5 & 6.8 & 3.6 & 5.2 & 3.4 & 4.7 & 3.3 & 4.5 & 3.4 & 4.4 & 3.4 & 4.4 & 3.5 & 4.4 & 3.6 & 4.4 \\
\hline Republic of Korea & 1.8 & 3.0 & 1.4 & 2.3 & 1.4 & 2.1 & 1.4 & 2.1 & 1.6 & 2.2 & 1.6 & 2.2 & 1.6 & 2.2 & 1.7 & 2.2 \\
\hline $\begin{array}{l}\text { South Asia } \\
\text { India }\end{array}$ & 30.4 & 30.4 & 18.5 & 18.5 & 14.5 & 14.5 & 11.7 & 117 & 97 & 99 & 83 & 87 & 72 & 79 & 6.5 & 72 \\
\hline Nepal & 75.0 & 75.0 & 68.8 & 69.0 & 63.1 & 68.0 & 58.1 & 66.1 & 53.5 & 63.4 & 49.3 & 59.9 & 45.1 & 55.7 & 41.0 & 50.9 \\
\hline Sri Lanka & 17.8 & 17.8 & 11.7 & 12.2 & 9.6 & 10.3 & 8.1 & 8.9 & 7.0 & 7.9 & 6.2 & 7.1 & 5.6 & 6.5 & 5.2 & 6.0 \\
\hline Southeast Asia & & & & & & & & & & & & & & & & \\
\hline Indonesia & 51.5 & 51.5 & 47.7 & 47.7 & 44.4 & 44.4 & 41.3 & 41.3 & 38.3 & 38.9 & 35.3 & 37.1 & 32.5 & 35.0 & 29.8 & 32.7 \\
\hline Singapore & 7.8 & 13.3 & 7.4 & 12.4 & 7.6 & 12.4 & 7.7 & 12.4 & 7.9 & 12.4 & 8.0 & 12.4 & 8.1 & 12.4 & 8.2 & 12.4 \\
\hline Thailand & 44.7 & 61.2 & 44.5 & 64.2 & 42.6 & 63.1 & 41.2 & 60.4 & 39.4 & 56.1 & 36.4 & 50.6 & 32.5 & 44.1 & 28.0 & 37.1 \\
\hline
\end{tabular}

\begin{tabular}{|c|c|c|c|c|c|c|c|c|c|c|c|c|c|c|c|c|}
\hline & \multicolumn{16}{|c|}{$20-24$} \\
\hline & \multicolumn{2}{|c|}{$2010-2015$} & \multicolumn{2}{|c|}{$2015-2020$} & \multicolumn{2}{|c|}{$2020-2025$} & \multicolumn{2}{|c|}{$2025-2030$} & \multicolumn{2}{|c|}{$2030-2035$} & \multicolumn{2}{|c|}{$2035-2040$} & \multicolumn{2}{|c|}{$2040-2045$} & \multicolumn{2}{|c|}{$2045-2050$} \\
\hline & Case 1 & Case 2 & Case 1 & Case 2 & Case 1 & Case 2 & Case 1 & Case 2 & Case 1 & Case 2 & Case 1 & Case 2 & Case 1 & Case 2 & Case 1 & Case 2 \\
\hline $\begin{array}{l}\text { East Asia } \\
\text { Hong Kong, China }\end{array}$ & 24.0 & 41.9 & 18.7 & 30.2 & 17.6 & 26.8 & 16.9 & 24.6 & 16.8 & 23.5 & 17.3 & 23.5 & 17.8 & 23.5 & 18.2 & 23.5 \\
\hline PRC & 133.6 & 181.1 & 127.6 & 168.5 & 122.5 & 158.2 & 114.6 & 145.4 & 104.0 & 129.9 & 90.7 & 111.8 & 75.2 & 91.9 & 59.0 & 71.3 \\
\hline Japan & 34.4 & 51.7 & 30.5 & 43.8 & 29.8 & 41.2 & 29.5 & 39.6 & 29.7 & 38.8 & 30.3 & 38.8 & 30.9 & 38.8 & 31.3 & 38.8 \\
\hline $\begin{array}{l}\text { Republic of Korea } \\
\text { South Asia }\end{array}$ & 17.2 & 28.7 & 10.7 & 16.9 & 9.4 & 14.2 & 8.9 & 12.9 & 9.1 & 12.8 & 9.3 & 12.7 & 9.5 & 12.7 & 9.7 & 12.7 \\
\hline India & 199.0 & 199.0 & 198.8 & 198.8 & 191.2 & 191.2 & 183.1 & 183.1 & 175.0 & 178.6 & 166.6 & 175.9 & 158.3 & 171.7 & 149.8 & 166.3 \\
\hline Nepal & 174.3 & 174.3 & 174.1 & 174.7 & 166.9 & 180.0 & 161.0 & 183.2 & 155.8 & 184.4 & 151.1 & 183.6 & 146.2 & 180.6 & 141.1 & 175.2 \\
\hline $\begin{array}{l}\text { Sri Lanka } \\
\text { Southeast Asia }\end{array}$ & 68.6 & 68.6 & 48.5 & 50.3 & 40.9 & 44.0 & 35.4 & 39.1 & 31.3 & 35.3 & 28.4 & 32.6 & 26.5 & 30.6 & 25.2 & 29.4 \\
\hline Indonesia & 130.2 & 130.2 & 121.9 & 121.9 & 114.9 & 114.9 & 108.7 & 108.7 & 103.2 & 104.9 & 98.0 & 102.8 & 93.3 & 100.4 & 89.0 & 97.6 \\
\hline Singapore & 40.3 & 68.6 & 42.6 & 70.9 & 43.4 & 70.9 & 44.2 & 70.9 & 44.9 & 70.9 & 45.6 & 70.9 & 46.2 & 70.9 & 46.7 & 70.9 \\
\hline Thailand & 80.7 & 110.4 & 70.1 & 101.0 & 65.1 & 96.5 & 63.0 & 92.3 & 61.8 & 88.1 & 60.5 & 84.0 & 58.9 & 79.8 & 57.0 & 75.6 \\
\hline
\end{tabular}




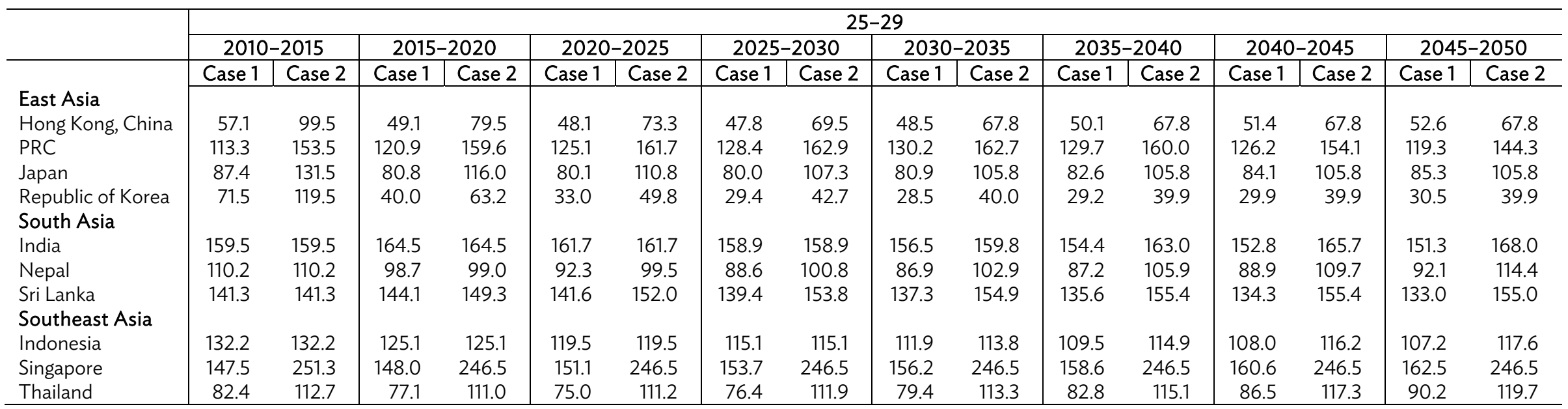

\begin{tabular}{|c|c|c|c|c|c|c|c|c|c|c|c|c|c|c|c|c|}
\hline & \multicolumn{16}{|c|}{$30-34$} \\
\hline & \multicolumn{2}{|c|}{$2010-2015$} & \multicolumn{2}{|c|}{$2015-2020$} & \multicolumn{2}{|c|}{$2020-2025$} & \multicolumn{2}{|c|}{$2025-2030$} & \multicolumn{2}{|c|}{$2030-2035$} & \multicolumn{2}{|c|}{$2035-2040$} & \multicolumn{2}{|c|}{$2040-2045$} & \multicolumn{2}{|c|}{$2045-2050$} \\
\hline & Case 1 & Case 2 & Case 1 & Case 2 & Case 1 & Case 2 & Case 1 & Case 2 & Case 1 & Case 2 & Case 1 & Case 2 & Case 1 & Case 2 & Case 1 & Case 2 \\
\hline East Asia & & & & & & & & & & & & & & & & \\
\hline Hong Kong, China & 95.1 & 165.8 & 109.8 & 177.8 & 118.6 & 180.9 & 125.6 & 182.7 & 131.2 & 183.6 & 135.5 & 183.6 & 139.2 & 183.6 & 142.3 & 183.6 \\
\hline PRC & 40.1 & 54.4 & 42.9 & 56.6 & 47.3 & 61.1 & 53.8 & 68.3 & 62.9 & 78.5 & 74.7 & 92.1 & 89.3 & 109.1 & 106.5 & 128.8 \\
\hline Japan & 96.5 & 145.2 & 101.4 & 145.6 & 105.1 & 145.2 & 108.1 & 145.0 & 111.0 & 145.1 & 113.3 & 145.1 & 115.4 & 145.1 & 117.1 & 145.1 \\
\hline Republic of Korea & 112.4 & 187.9 & 128.8 & 203.4 & 134.7 & 203.1 & 139.5 & 202.5 & 144.6 & 203.0 & 148.8 & 203.3 & 152.3 & 203.3 & 155.3 & 203.3 \\
\hline South Asia & & & & & & & & & & & & & & & & \\
\hline India & 69.3 & 69.3 & 61.3 & 61.3 & 57.4 & 57.4 & 54.8 & 54.8 & 53.4 & 54.5 & 53.0 & 55.9 & 53.7 & 58.3 & 55.5 & 61.6 \\
\hline Nepal & 55.5 & 55.5 & 41.6 & 41.7 & 36.7 & 39.6 & 34.0 & 38.7 & 32.9 & 38.9 & 33.3 & 40.4 & 35.0 & 43.2 & 38.2 & 47.4 \\
\hline Sri Lanka & 120.3 & 120.3 & 127.0 & 131.7 & 126.9 & 136.3 & 127.1 & 140.2 & 127.2 & 143.5 & 127.6 & 146.2 & 128.4 & 148.5 & 129.0 & 150.3 \\
\hline Southeast Asia & & & & & & & & & & & & & & & & \\
\hline Indonesia & 103.0 & 103.0 & 98.0 & 98.0 & 94.3 & 94.3 & 91.7 & 91.7 & 90.2 & 91.7 & 89.6 & 94.0 & 89.8 & 96.7 & 91.0 & 99.8 \\
\hline Singapore & 190.1 & 323.7 & 193.6 & 322.4 & 197.6 & 322.4 & 201.0 & 322.4 & 204.3 & 322.4 & 207.4 & 322.4 & 210.0 & 322.4 & 212.6 & 322.4 \\
\hline Thailand & 62.6 & 85.7 & 63.8 & 91.9 & 64.6 & 95.7 & 68.3 & 100.1 & 73.7 & 105.1 & 79.5 & 110.5 & 85.7 & 116.2 & 92.2 & 122.3 \\
\hline
\end{tabular}




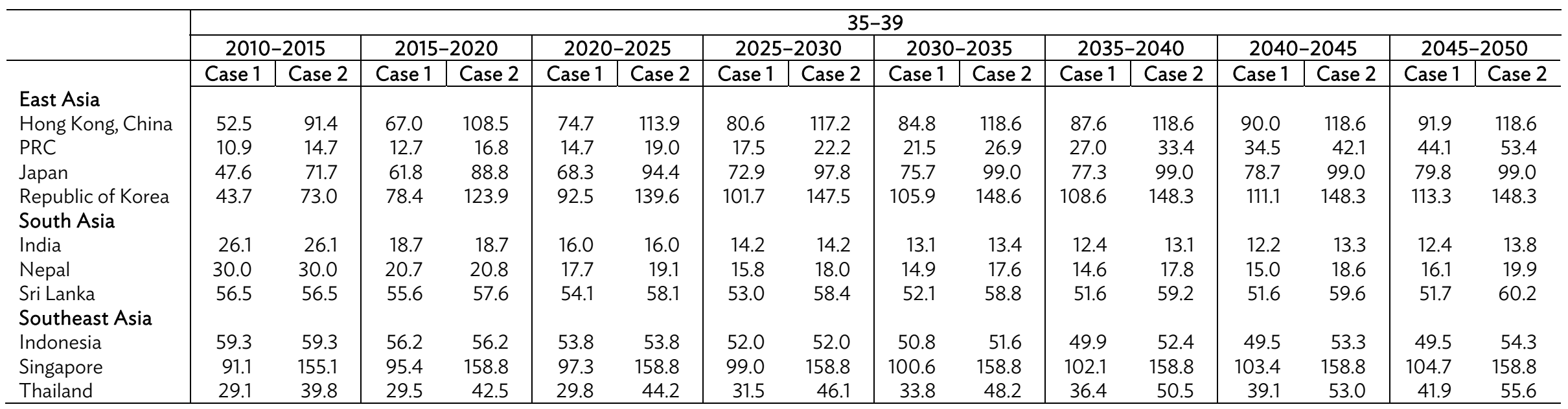

\begin{tabular}{|c|c|c|c|c|c|c|c|c|c|c|c|c|c|c|c|c|}
\hline & \multicolumn{16}{|c|}{$40-44$} \\
\hline & \multicolumn{2}{|c|}{$2010-2015$} & \multicolumn{2}{|c|}{$2015-2020$} & \multicolumn{2}{|c|}{$2020-2025$} & \multicolumn{2}{|c|}{$2025-2030$} & \multicolumn{2}{|c|}{$2030-2035$} & \multicolumn{2}{|c|}{$2035-2040$} & \multicolumn{2}{|c|}{$2040-2045$} & \multicolumn{2}{|c|}{$2045-2050$} \\
\hline & Case 1 & Case 2 & Case 1 & Case 2 & Case 1 & Case 2 & Case 1 & Case 2 & Case 1 & Case 2 & Case 1 & Case 2 & Case 1 & Case 2 & Case 1 & Case 2 \\
\hline $\begin{array}{l}\text { East Asia } \\
\text { Hong Kong, China }\end{array}$ & 8.6 & 15.0 & 11.8 & 19.0 & 13.5 & 20.5 & 14.9 & 21.7 & 16.0 & 22.3 & 16.5 & 22.3 & 16.9 & 22.3 & 17.3 & 22.3 \\
\hline PRC & 3.6 & 4.9 & 6.1 & 8.0 & 7.6 & 9.8 & 9.0 & 11.4 & 9.8 & 12.3 & 10.7 & 13.2 & 11.0 & 13.4 & 10.7 & 12.9 \\
\hline Japan & 8.5 & 12.8 & 14.1 & 20.2 & 16.8 & 23.3 & 19.0 & 25.4 & 20.2 & 26.4 & 20.6 & 26.4 & 21.0 & 26.4 & 21.3 & 26.4 \\
\hline $\begin{array}{l}\text { Republic of Korea } \\
\text { South Asia }\end{array}$ & 4.5 & 7.5 & 6.3 & 9.9 & 7.2 & 10.9 & 8.2 & 12.0 & 9.4 & 13.1 & 9.6 & 13.1 & 9.8 & 13.1 & 10.0 & 13.1 \\
\hline India & 8.9 & 8.9 & 5.3 & 5.3 & 4.2 & 4.2 & 3.4 & 3.4 & 3.0 & 3.0 & 2.6 & 2.8 & 2.5 & 2.7 & 2.4 & 2.6 \\
\hline Nepal & 15.3 & 15.3 & 11.8 & 11.9 & 10.4 & 11.2 & 9.4 & 10.7 & 8.8 & 10.4 & 8.4 & 10.2 & 8.2 & 10.2 & 8.3 & 10.3 \\
\hline Sri Lanka & 15.5 & 15.5 & 15.4 & 15.9 & 14.9 & 16.0 & 14.5 & 16.0 & 14.1 & 15.9 & 13.8 & 15.8 & 13.5 & 15.7 & 13.3 & 15.5 \\
\hline $\begin{array}{l}\text { Southeast Asia } \\
\text { Indonesia }\end{array}$ & 18.5 & 18.5 & 17.4 & 17.4 & 16.5 & 16.5 & 15.7 & 15.7 & 15.1 & 15.3 & 14.5 & 15.3 & 14.1 & 15.1 & 13.7 & 15.0 \\
\hline Singapore & 15.9 & 27.0 & 16.7 & 27.9 & 17.1 & 27.9 & 17.4 & 27.9 & 17.7 & 27.9 & 17.9 & 27.9 & 18.2 & 27.9 & 18.4 & 27.9 \\
\hline Thailand & 7.1 & 9.8 & 6.4 & 9.2 & 6.1 & 9.1 & 6.2 & 9.1 & 6.4 & 9.1 & 6.6 & 9.2 & 6.9 & 9.4 & 7.3 & 9.7 \\
\hline
\end{tabular}

PRC= People's Republic of China.

Source: Authors' calculations based on data from the United Nations, Department of Economic and Social Affairs, Population Division. Special Aggregates.

https://esa.un.org/unpd/wpp/Download/SpecialAggregates/Ecological/ 


\section{BIBLIOGRAPHY}

Andreev, Kirill, Vladimíra Kantorová, and John Bongaarts. 2013. Demographic Components of Future Population Growth. United Nations, Department of Economic and Social Affairs, Population Division Technical Paper No. 2013/3.

Asian Development Bank (ADB). 2011. Asian Development Outlook 2011: Update. Manila.

- 2012. Key Indicators for Asia and the Pacific 2012. Manila.

2016. Asian Development Outlook 2016. Manila.

Bloom, David, David Canning, and Pia Malaney. 2000. "Population Dynamics and Economic Growth in Asia." Population and Development Review 26: 257-90.

Bloom, David, David Canning, and Jaypee Sevilla. 2003. The Demographic Dividend: A New Perspective on the Economic Consequences of Population Change. Pittsburgh: RAND Corporation.

Burtless, Gary. 2013. "The Impact of Population Aging and Delayed Retirement on Workforce Productivity." Center for Retirement Research Working Paper No. 2013-11.

Kleiman, Ephraim. 1967. “A Standardized Dependency Ratio.” Demography 4 (2): 876-93.

Menon, Jayant, and Anna Melendez. 2009. "Ageing in Asia: Trends, Impacts and Responses.” ADB Working Paper Series on Regional Economic Integration No. 25.

Park, Donghyun, and Kwanho Shin. 2011. "Impact of Population Aging on Asia's Future Growth.” ADB Economics Working Paper Series No. 281.

Radović-Marković, Mirjana. 2013. "An Aging Workforce: Employment Opportunities and Obstacles." http://www.cadmusjournal.org/files/pdfreprints/vol1issue6/reprint-cj-v1-i6-an-aging-workforce -mradovick.pdf

United Nations, Department of Economic and Social Affairs, Population Division. Special Aggregates. https://esa.un.org/unpd/wpp/Download/SpecialAggregates/Ecological/

_2013a. National Transfer Accounts Manual: Measuring and Analysing the Generational Economy. New York.

2013b. World Population Ageing 2013. New York.

_. 2015a. World Population Ageing 2015. New York.

_. 2015b. World Population Prospects: The 2015 Revision, Key Findings and Advance Tables. New York.

White, Stanley. 2015. “Japan Targets Boosting Birth Rate to Increase Growth.” Reuters (US edition). November 12.

World Bank. 2016. Live Long and Prosper: Aging in East Asia and Pacific. Washington, DC.

Zwick, Thomas, Christian Göbel, and Jan Fries. 2013. Age-Differentiated Work Systems Enhance Productivity and Retention of Old Employees. In Age-Differentiated Work Systems, edited by Christopher Marc Schlick, Ekkehart Frieling, and Jürgen Wegge, 25-44. Springer-Verlag Berlin Heidelberg. 


\section{How to Fill the Working-Age Population Gap in Asia: A Population Accounting Approach}

World populations are aging-with the speed and extent of the demographic shift varying across developed and developing economies. Extending the retirement age is expected to reduce the dependency ratio by increasing the number of workers relative to the number of consumers. Meanwhile, increasing immigration will require proactive efforts in both host and source economies. While increasing fertility rates may entail additional short-term burdens on the economy, policy makers need to take urgent action to avoid being trapped in the vicious cycle of shrinking populations and rising dependency ratios.

\section{About the Asian Development Bank}

ADB's vision is an Asia and Pacific region free of poverty. Its mission is to help its developing member countries reduce poverty and improve the quality of life of their people. Despite the region's many successes, it remains home to half of the world's extreme poor. ADB is committed to reducing poverty through inclusive economic growth, environmentally sustainable growth, and regional integration.

Based in Manila, ADB is owned by 67 members, including 48 from the region. Its main instruments for helping its developing member countries are policy dialogue, loans, equity investments, guarantees, grants, and technical assistance. 